\title{
Corticocortical Systems Underlying High-Order Motor Control
}

\author{
(1DAlexandra Battaglia-Mayer ${ }^{1}$ and Roberto Caminiti ${ }^{1,2}$ \\ ${ }^{1}$ Department of Physiology and Pharmacology, University of Rome, Sapienza, 00185 Rome, Italy, and ${ }^{2}$ Neuroscience and Behavior Laboratory, Istituto \\ Italiano di Tecnologia, 00161 Rome, Italy
}

Cortical networks are characterized by the origin, destination, and reciprocity of their connections, as well as by the diameter, conduction velocity, and synaptic efficacy of their axons. The network formed by parietal and frontal areas lies at the core of cognitive-motor control because the outflow of parietofrontal signaling is conveyed to the subcortical centers and spinal cord through different parallel pathways, whose orchestration determines, not only when and how movements will be generated, but also the nature of forthcoming actions. Despite intensive studies over the last 50 years, the role of corticocortical connections in motor control and the principles whereby selected cortical networks are recruited by different task demands remain elusive. Furthermore, the synaptic integration of different cortical signals, their modulation by transthalamic loops, and the effects of conduction delays remain challenging questions that must be tackled to understand the dynamical aspects of parietofrontal operations. In this article, we evaluate results from nonhuman primate and selected rodent experiments to offer a viewpoint on how corticocortical systems contribute to learning and producing skilled actions. Addressing this subject is not only of scientific interest but also essential for interpreting the devastating consequences for motor control of lesions at different nodes of this integrated circuit. In humans, the study of corticocortical motor networks is currently based on MRI-related methods, such as resting-state connectivity and diffusion tract-tracing, which both need to be contrasted with histological studies in nonhuman primates.

\section{Introduction}

The importance of corticocortical connections in cognitive functions has been recognized for more than a century. The WernickeLichtheim's model (Wernicke, 1874; Lichtheim, 1885) of conduction aphasia was the first attempt to assign specific functions to an individual fiber tract of the human brain, that is, the arcuate fascicle linking Wernicke's area in the parietal lobe and Broca's area in the frontal lobe. Conduction aphasia is characterized by phonological errors that distort the sound of words (e.g., "halotopter" for helicopter) and impair naming and repetition of words and nonwords, while preserving relatively fluent speech and comprehension of language (for a recent review, see Coslett and Schwartz, 2018). Lichtheim (1885) schematically interpreted conduction aphasia as consequence of the interruption of the link between auditory and motor speech centers, therefore, of the selection and control of auditory-speech sounds. In today's terms, this would be considered a disorder of auditory-motor integration. Conduction aphasia is often associated with damage of the white matter underlying the posterior part of the superior

\footnotetext{
Received Aug. 15, 2018; revised March 5, 2019; accepted March 8, 2019.

This work was supported by University of Rome Sapienza Protocol RM11715C7891F89B to A.B.-M., Ministero dell'Istruzione, dell'Università e della Ricerca of Italy Protocol 2015AWSW2Y_002 to R.C., and the Italian Institute of Technology. We thank Drs. M.V. Chafee, T. Komiyama, S. Safavi, N. Logothetis, M.A. Smith, H. Scherberger, B. Dann, and their collaborators for permission to use materials from their work; Dr. G. lannetti for critical comments on the manuscript; and Dr. I. Lacal for the support provided in the literature search and update.

The authors declare no competing financial interests.

Correspondence should be addressed to Alexandra Battaglia-Mayer at alexandra.battagliamayer@uniroma1.it. https://doi.org/10.1523/JNEUROSCI.2094-18.2019

Copyright $\odot 2019$ the authors
}

temporal gyrus and/or of the supramarginal gyrus in the left hemisphere (Coslett and Schwartz, 2018).

Despite vivid criticisms (for review, see Catani and Mesulam, 2008), this conceptual approach, that is, attributing the consequences of brain lesion to disruption of communication between cortical areas, has exerted a long-lasting influence on the neurological studies of the 20th century, as testified, for example, by Bálint's (1909) classic case report of a patient suffering from defective visual guidance of eye-hand action (optic ataxia); inability to change gaze in a voluntary fashion (psychic paralysis of gaze); and lack of attention to stimuli and events to the left of the fixation point (unilateral spatial neglect). Importantly, the patient was free of primary sensory and motor deficits and of oculomotor paralysis. At the postmortem examination, the brain showed signs of a bilateral stroke around the parieto-occipital sulcus and the angular gyrus, interpreted as responsible of the breakdown of the parietofrontal association functions (for recent reviews, see Rossetti and Pisella, 2018), hence as a disorder of visuo-motor integration. For many years unnoticed, this remarkable piece of work was brought to the attention of the scientific community as “Bálint's syndrome” by Hécaen and de Ajuriaguerra (1954).

A tremendous boost to the disconnection hypothesis came with the publication by Roger W. Sperry and his collaborators (Gazzaniga et al., 1962) of the case of patient W.J. who had suffered with intractable epilepsy until he underwent section of the corpus callosum and forebrain commissures to prevent the spread of seizures to both hemispheres. After recovery, this "splitbrain" patient was tested with tachistoscopic presentation of visual stimuli, such as the word "face," first confined to the left 
hemisphere, which was dominant for language. When asked what he saw, the patient responded "face." However, when the word was presented to the right hemisphere, the patient responded he saw nothing. Indeed, after the section of the corpus callosum, the right hemisphere could not share anymore the information with the left dominant one. Despite this, W.J. was able to draw a face with the left hand, which is controlled by the right hemisphere, where the word "face" was projected. This study was a giant leap forward for the analysis of brain lateralization of functions, and it revealed, for the first time, the role of the corpus callosum in the interhemispheric transfer of information in humans (Sperry, 1968).

Based on the knowledge accumulated over more than a century and thanks to a large recollection of the neurological studies and of their systematic association with anatomical lesions, Geschwind (1965) closed the loop by formalizing the concept of "disconnection syndrome." He also extended this concept to the lesion of the association cortex, which disconnect primary sensory and motor areas from the processing of information typical of higher-order areas (for review, see Catani and Mesulam, 2008), such as the angular gyrus of the parietal lobe, a multimodal hub for information processing and transfer. After years of debate, this perspective and its clinical implications have been reviewed and updated (Catani and Mesulam, 2008; Carrera and Tononi, 2014; Silasi and Murphy, 2014) from the perspective offered by computational analysis of cortical networks through graph theory (Bullmore and Sporns, 2009), which provides formal tools to describe how information can be distributed across different nodes of a cortical network.

The physiological implication of the disconnection hypothesis, along with insights gleaned from modern studies of cortical connectivity in nonhuman primates, is that signal processing in individual cortical areas has networkwide influences thanks to corticocortical connections. Hence, brain functions reside in the operations of distributed systems (Mountcastle, 1978), rather than of individual areas. This logic of cortical connections has an important evolutionary coté because it favors the homeostatic regulation of brain circuits (Turrigiano, 1999; Marder and Goaillard, 2006; Keck et al., 2013). This, in turn, mitigates the dramatic consequences of brain lesions, allowing partial recovery of function.

Despite the acknowledged importance of interareal connections in complex behaviors, most studies of such functions focus on the role of individual areas. Therefore, this Viewpoints article discusses the anatomofunctional design and role in motor control of different parietofrontal areas and networks in macaque monkeys and rodents, keeping in mind, however, that not all rodents are the same (Krubitzer at al., 2011). We will also discuss the transthalamic modulation of corticocortical communication, first hypothesized by Guillery (1995). As will be seen, this influence adds flexibility to corticocortical computations. Our position is that the orchestration of neural activity of different areas by corticocortical connections lies at the core of cognitive-motor control and guide action occurring in different contexts.

We describe essential features of network architecture and how these subserve functional components. Special attention will be devoted to interareal communication, as estimated by the characterization of axon diameter and conduction delays between different areas and neural centers (Caminiti et al., 2009, 2013; Tomasi et al., 2012; Innocenti et al., 2014, 2019). Furthermore, we discuss recent data on functional connectivity in nonhuman primates. This information is necessary to shed light not only on conscious and nonconscious visuospatial analysis (Krav- itz et al., 2011) but also on a large variety of other brain functions, such as visual processing (Stoelzel et al., 2017), hippocampal memory formation (Grewe et al., 2017) and communication with the amygdala (Xu et al., 2016), parietohippocampal interactions underlying spatial cognition (Whitlock et al., 2008), and many others. This knowledge will be essential to understand the neural disorders that arise from the temporal disruption of cortical communication.

\section{Five systems of parietofrontal connections underlie cognitive-motor control}

The connections between the areas of posterior parietal cortex (PPC) and frontal cortex (FC) involved in motor control in monkeys have been determined through anatomical tracing studies (Caminiti et al., 2017). These have inspired physiological investigations and now form a large dataset essential to validate empirical results obtained using MRI-based diffusion tract-tracing and resting-state connectivity (Rushworth et al., 2006; Mars et al., 2011, 2018; Goulas et al., 2012; Sallet et al., 2013; Neubert et al., 2014; Ruschel et al., 2014; Vijayakumar et al., 2019), which are essential tools for the analysis of human brain networks (Van Essen, 2002; Sporns, 2012; Markov et al., 2013; Van Essen et al., 2013). We start by illustrating the mesoscale organization of parietofrontal connections involved in executive functions and motor control and later discuss the functional operations performed by their parent areas.

In recent years, hierarchical cluster analysis has been used in nonhuman primates (NHPs) to aggregate prefrontal, frontal, and parietal areas into clusters based on their connectivity profile (Averbeck and Seo, 2008; Averbeck et al., 2009; Caminiti et al., 2017). It has been found that each identified parietal cluster includes areas sharing certain functional properties and is preferentially connected to physiologically congruent frontal clusters. Such properties can relate to visual target sensitivity, encoding movement parameters, preparatory activity, working-memory modulation, etc. Therefore, parietal and frontal clusters can be regarded as nodes of neural domains that process different inputs and distribute several outputs. Input signals select the area of access (entry point) to the network, which distributes output information to several neural centers, giving rise to a multiplicity of processing streams. These encode actions of different complexity, from reaching and grasping to object manipulation and construction, tool use, oculomotor control, visuospatial attention, performance monitoring, as well as ethologically relevant functions underlying defensive behavior, and perform action observation-execution matching, as in the case of the mirror system. Parietofrontal streams can hardly be considered private routes devoted to just one function; rather, they are informationprocessing lines used for multiple purposes (Battaglia-Mayer and Caminiti, 2018; Borra and Luppino, 2018), as suggested by the multiplicity and functional heterogeneity of neural ensembles (Daitch and Parvizi, 2018) that they connect and by the complex organization of the intraparietal sulcus and parieto-occipital cortex in humans (Richter et al., 2019).

\section{The dorsal reaching system (DRS)}

Beyond locomotion, hand reaching is the most common form of daily action in primates. The underlying neural circuits include corticocortical connections linking areas that in most instances give rise to different descending pathways. These convey the outflow of parietofrontal operations to subcortical centers and to the spinal cord. The analysis of the functional properties of cells in the many reach-related parietal and frontal areas and the study of 
their connections indicate that fast reaching and its online control are primarily encoded by a DRS (Caminiti et al., 2017), which also incorporate a grasping-related component (Filippini et al., 2017; Breveglieri et al., 2018; Nelissen et al., 2018), probably subserving an early coordination of reaching and grasping. This view on the DRS is also supported by the effects of reversible inactivation in monkeys, which mimics the defective online control of eye and arm movement (BattagliaMayer et al., 2013) typical of patients with parietal lesions resulting in optic ataxia (Balint, 1909; Pisella et al., 2000; Gréa et al., 2002; Buiatti et al., 2013).

Successful reaching requires the fusion of somatosensory information on hand position with visual signals concerning target location. A key region for this integration is the superior parietal lobule (SPL), where visual information arriving at areas $\mathrm{V} 6 \mathrm{~A}$ and $7 \mathrm{~m}$ from extrastriate cortex (and/or from the n. pulvinar caudalis) can be combined with somatosensory signals about hand position relayed through anterior parietal areas S1/PE (and/or through the $\mathrm{n}$. lateralis posterior and pulvinar oralis). Therefore, the parieto-occipital areas can be considered as eye-hand integrative domains that allow the DRS and other parietofrontal processing lines to continuously access visual information. The coordinate transformation from retinal to limb coordinates underlying fast reaching seems to occur in the arm-dominant domain of the SPL, formed by areas PEc, PEa, MIP (Caminiti et al., 2017), which is, in part, coextensive with the so-called parietal reach region (PRR) (Snyder et al., 1997). In the arm-dominant domain of the DRS, neurons are influenced, by visual, eye, and hand signals, although with different strength, depending on their anteroposterior location in the SPL (Johnson et al., 1989; Battaglia-Mayer et al., 2001). The outflow of this domain (Fig. 1) (Johnson et al., 1996; Matelli et al., 1998; Battaglia-Mayer et al., 2001) is addressed in a gradient-like fashion to the dorsal premotor cortex (PMd; F2), supplementary motor cortex (SMA; F3), rostral (CMAr), and ventral cingulate motor areas (CMAv). These are all frontal premotor areas projecting to the motor cortex (M1) (Picard and Strick, 1996). Together, they shape the frontal motor output domain, thanks to their parallel projections to the spinal cord. Therefore, the DRS emerges from the connectivity linking parietal and frontal hand-dominant domains, each with its specific role, and influences the motor periphery through multiple frontal and parietal descending systems.

\section{The lateral reaching system (LARS)}

The pattern of corticocortical connections of the inferior parietal lobule sculpt a stream formed by the parieto-occipital area Opt, as the entry point, and by area PG and its projection to the armdominant domain of the DRS (Fig. 1). This conveys the information processed in the LARS to the FC motor output domain, providing an example of a segment of the parietofrontal system subserving complementary processing streams. The LARS can therefore be considered as a substream of the DRS recruited when the task requires eye and hand movements embedded in actions that unfold over long times and that requires continuous visuospatial analysis and monitoring, as well as evaluation of in- termediate outcomes. Among these functions are object construction (Chafee et al., 2005, 2007; Crowe et al., 2008), analysis and solution of visual mazes (Crowe et al., 2004a, 2005), tool use (Iriki et al., 1996), and interception of moving targets (Merchant et al., 2003), which can benefit from input signals conveyed by the motion-sensitive areas middle temporal (MT) and middle superior temporal (MST). In infant marmosets, the lesion of a transient retino-pulvinar-MT projection impairs reach and grasping during adult life (Mundinano et al., 2018). In humans, inferior parietal lobule lesions centered on the areas (PGa, PGp) of the posterior group (Caspers et et al., 2013) result in constructional apraxia (Kleist, 1934; Gainotti and Trojano, 2017), among other deficits. Finally, the expanded representation of contralateral directional space in Opt and PG (Battaglia-Mayer et al., 2005) explains why its collapse might be responsible for directional hypokinesia (Mattingley et al., 1992; Heilman et al., 2000), which is a deficit of motor intention for reaches toward contralesional space in parietal patients with neglect.

\section{The lateral grasping system (LGS)}

Reaching is, in most instances, aimed at grasping and manipulating objects of interest. In NHPs, the LGS (Fig. 1) is formed by parietal area PFG (entry point), AIP, and SII, by premotor area F5a, prefrontal areas 46 ventrocaudal, and part of area 12 . The LGS is regarded as a privileged network to encodes purposeful hand actions (for dedicated reviews, see Borra et al., 2017; Borra and Luppino, 2018). Recent studies suggest that it can be recruited by inputs from area F6 (Lanzilotto et al., 2016). Embedded in this network is the mirror system, which uses area PFG as an intermediate node for information transfer from superior temporal areas to F5 (Rizzolatti et al., 2014).

\section{The oculomotor intention and attention system (OAS)}

The OAS (Caminiti et al., 2015, 2017; Battaglia-Mayer and Caminiti, 2018, and the references therein) is formed by areas Opt, LIP, and MST and their connections with the frontal and supplementary eye fields, as eye motor output and monitoring domains. This complex network offers a clear example of heterogeneity of functions. Information processing and transfer in the 
OAS concern oculomotor intention and control, performance monitoring, selective visual attention, saliency and novelty, visuo-acoustic orienting and communication, decision-making and working-memory. The OASs' visual functions relate to the analysis of $3 \mathrm{D}$ object properties, visual motion, heading perception, and visual motion processing for manual interception of moving targets. It is therefore not surprising that, in humans, damage to a tentative homologous system, which has expanded significantly in evolution, produces diverse deficits, spanning from gaze apraxia, hemispatial neglect (Vallar and Bolognini, 2014), and extinction, to dyslexia, among others, which cannot be found in monkeys. Finally, the outcome of the transformation into motor intentions of action choices, which depend on reward and economic decision (Cai and Padoa-Schioppa, 2014), and the related error signaling (for comprehensive reviews, see Schultz, $2015,2016)$ can be routed to the motor output through the OAS, which offers an outflow pathway to the influences exerted by the ventral orbitofrontal cortex on the selection of behavioral goals and strategies.

\section{The peripersonal action fields system (PAFS)}

The convergence and directional alignment of somatosensory information from parietal area $\mathrm{PE}$ and visual motion signals from MSTd on ventral intraparietal area (VIP), together with vestibular information from parieto-insular vestibular and visual sylvian cortex, confer to this circuit complex multimodal properties related to the analysis of visual objects (Colby et al., 1993; Duhamel et al., 1998) moving toward specific body parts, as well as to heading direction and perception (Schlack et al., 2002, 2005; Britten, 2008; Chen et al., 2011, 2013, 2016). VIP projects to ventral premotor area F4 and can implement the visuomotor transformation aimed to create or avoid contact between objects and the body (Bufacchi and Iannetti, 2018), thus contributing to shape defensive behavior (Graziano and Cooke, 2006; Graziano, 2016; Kaas et al., 2018) and other ethologically relevant functions, such as reaching to bring food to the mouth (Gentilucci et al., 1988; Fogassi et al., 1996). Thanks to the functions encoded by VIP, this stream also allows to estimate the numerosity (Nieder and Dehaene, 2009; Nieder, 2016) of targets for potential actions around the body. In conclusion, the PAFS seems to encode the manifold peripersonal action fields and their varying features, whose numerical values depend on many factors, such as behavioral and ethological relevance of actions, stimulus valence and proximity, social and economic cues, tool use, and locomotion (for a recent conceptualization, see Bufacchi and Iannetti, 2018), in other words, from a "world full of action choices" (Cisek and Kalaska, 2010). Not surprisingly, lesion of postarcuate cortex, including F4, results in neglect of objects in peripersonal space (Rizzolatti et al., 1983; Schieber, 2000).

A study based on hierarchical cluster analysis analysis of frontal and parietal areas defined from resting-state connectivity in macaques confirms the existence of the main parietofrontal streams described above, that is, DRS, LGS, and OAS (Vijayakumar et al., 2019), suggesting that this approach remains a promising tool for studies in humans, to be systematically validated by structural analysis of neural circuits in NHPs.

\section{Corticocortical axons and conduction delays}

In monkeys, the parietofrontal projections are formed by thin myelinated axons and by a small contingent of unmyelinated ones, whose caliber depends on both the area of origin and termination (Innocenti et al., 2014). As an example, the area PEc fibers addressed to M1, F2, and CMAd obey this rule (Innocenti et al., 2014) because those directed to M1 and F2 have a similar size (mean $0.95 \mu \mathrm{m}$ ), whereas axons to CMAd are thinner (mean $0.77 \mu \mathrm{m}$ ). The resulting conduction velocity is $\sim 6.8 \mathrm{~m} / \mathrm{s}$ for the $\mathrm{PEc}$ messages addressed to M1 and F2, and $6.3 \mathrm{~m} / \mathrm{s}$ to CMAd. By measuring the path length, the estimated delays from PEc are 1.9 ms to M1, 3.3 ms to F2, and 3.4 ms to CMAd. The actual delays can be longer to the time required for synaptic transmission.

Each of these projections is formed by axons of different diameter, which implies that the information they convey arrives at the target in a temporally dispersed fashion. The impact of this temporal heterogeneity can probably be understood in terms of evolution. Indeed, one of the several potential effects of this structural-functional relation observed when analyzing callosal connections across macaques, chimpanzees, and humans (Caminiti et al., 2009, 2013; for review, see Innocenti et al., 2016) is that, in the latter, evolution has expanded by threefold the conduction delays between the hemispheres. This is the result of a larger increase in connection length, hence temporal delays, than in axon diameters, therefore in conduction velocity, across these species. Beyond elongating the time for interhemispheric communication, evolution might have produced a dynamic expansion of the neural assemblies generated by cortical connectivity to encode task-related variables. Indeed, action potential with different temporally dispersed conduction delays generates postsynaptic bursts of different duration, and therefore can adjust the cycle of cortical oscillations. Contrasting synchronous versus asynchronous neural groups (Carmeli et al., 2007) can be a way to expand the number of functional assemblies in the cortex.

It is our hypothesis that, in the parietofrontal system, a network dynamic similar to that of callosal connections favors a simultaneous representation of plans for eye and hand action in different reference frames (Battaglia-Mayer et al., 2003) because it multiplies in a time- and task-dependent fashion the number of local neuronal groups that can be recruited for parietofrontal operations. Temporally dispersed conduction delays characterize corticocortical communication also in the visual system (Swadlow et al., 1978) and represent a general property of communication within the CNS. Therefore, spatial and temporal heterogeneity might play a paramount role in encoding different functions, even within individual network nodes.

\section{Circuit analysis of visuomotor integration in the parietofrontal system}

As is typical of many cortical areas (Rockland, 2015), in macaque monkeys, the ipsilateral corticocortical connections arising from bands of pyramidal cells in the SPL areas (Johnson et al., 1989, 1996; Battaglia-Mayer et al., 2001) terminate as patches in layers I-IV (Jones et al., 1978; Leichnetz, 2001) of PMd and/or M1, where they synapse on pyramidal neurons and on inhibitory interneurons. As layer V pyramidal tract neurons (Ghosh and Porter, 1998), pyramidal cells in layer III of M1 display horizontal axons traveling for several millimeters (DeFelipe et al., 1986; Huntley and Jones, 1991) to arborize (Lund et al., 1993) on the apical dendrites of other pyramidal cells and on nonpyramidal, presumably inhibitory, interneurons (Keller, 1993; Keller and Asanuma, 1993). Their action is generally excitatory and is mediated by asymmetric synapses releasing glutamate or aspartate (Conti et al., 1987, 1988). However, the in vivo postsynaptic efficacy of corticocortical afferents can be weak because of a strong feedforward intracortical inhibition (Bruno and Simons, 2002).

Axon collaterals display profuse branching, suggesting that they influence distributed postsynaptic cell assemblies (Rockland, 2018). Arbors of nonpyramidal "basket," "chandelier," "bi- 
polar," and "bitufted" (Fairén et al., 1984) cells significantly contribute to M1 functions. Most of them are GABAergic and connect superficial and deep cortical layers within a narrow vertical column, with no profuse horizontal connections (DeFelipe and Jones, 1985). Others in M1, such as GABAergic "basket" cells, give rise to axon collaterals that travel for $>1 \mathrm{~mm}$ horizontally (Jones, 1975; DeFelipe et al., 1986), as in the visual cortex (Kisvárday and Eysel, 1992; Fitzpatrick, 1996). Thus, axon collaterals display varying spatial configurations and functions.

In monkeys' M1, axonal arbors terminate in cortical territories of partially overlapping topographical hand/arm representations (Huntley and Jones, 1991), thus providing a substrate for the orderly recruitment of motor cortical cells controlling the temporal coordination of shoulder, elbow, and wrist movements during reach-to-grasp actions (Kwan et al., 1978a,b). Individual M1 cells can control the movement of different fingers (Poliakov and Schieber, 1999), thanks to divergent axons influencing different motoneuronal pools (Shinoda et al., 1981). Therefore, in M1, horizontal connections can select and orchestrate the time-varying activity of different cortical assemblies based on the specific combination of finger movement required by the task, as during piano playing.

\section{Relevance of corticocortical connections for the functional organization of frontal and parietal areas}

In canonical cortical microcircuits, horizontal connections allow correlated neural activity. In a region of PFC where visual neurons tuned to object identity (Wilson et al., 1993; Asaad et al., 1998) coexist with genuine hand movement-related cells (Bruni et al., 2015; Simone et al., 2015), the correlated fluctuation of single-neuron activities occurs over long-range distances (Safavi et al., 2018) (Fig. 2A) compared with the limited-range correlational structure typical of sensory areas, such as V1 (Smith and Sommer, 2013) (Fig. 2B) and V4 (Smith and Kohn, 2008) (Fig. $2 C)$. It has been suggested that this arrangement might facilitate the higher-order integration processing of association areas and of executive functions.

On a mesoscale level, PPC and FC areas with similar activity types and functions, such as visual reaching (Johnson et al., 1996; Battaglia-Mayer et al., 2001; Archambault et al., 2009, 2011) (Fig. $3 A$ ), working memory (Chafee and Goldman-Rakic, 1998, 2000) (Fig. 3B), and motor goal retrieval (Martínez-Vázquez and Gail, 2018), tend to be linked by long ipsilateral connections. The quantitative study of the relationships between the spatial distributions of functional properties of neurons and of parietalfrontal projecting cells underlying visual reaching (Fig. 4) suggests that these projections are a natural substrate to confer matching properties to neurons in distant frontal areas, thereby for shaping their functional properties and, at the same time, the skeleton of a recurrent network. This view has also been stressed by Passingham et al. (2002), based on the hierarchical cluster analysis of examples of histological connectivity data from macaque and meta-analyses of fMRI studies in humans (Mars et al., 2018).

However, such similarities do not imply functional equivalence of parietal and frontal areas, as suggested by the consequence of brain lesions. Interesting examples can be found in studies of the DRS, LGS, and OAS. In many instances, the differences concern reference frame representation, timing of activation, neural dynamics, functional connectivity, and the uniqueness of the organization of microcircuits in the agranular FC.

\section{Reference frame representation}

Early work has shown that, in M1 (Caminiti et al., 1990), PMd (Caminiti et al., 1991), and parietal area 5 (Lacquaniti et al., 1995), 3D arm reaching is encoded in shoulder-centered coordinates. Moreover, in area 5, neural activity is tuned in an abstract spherical body-centered frame, with the azimuth, elevation, and distance of the hand encoded in a parallel fashion by different cell populations. A different coding scheme for reaching was proposed later, holding that, in PRR, which only partially overlaps the region of area 5 studied by Lacquaniti et al. (1995), neural activity encodes reach intentions in eye coordinates (Batista et al., 1999), leaving open the possibility of a progressive transformation from eye to hand coordinates in the parietal functional gradient. Subsequent studies of parietal areas V6A, 7m, and PEc (Battaglia-Mayer et al., 2000, 2001) based on a multitask approach showed that visual, eye, and hand reach-related signals influencing individual cells display similar directional tuning, a property referred to as global tuning field. These properties are ideally suited, not only for computing the relative position of the target, hand, and eye, but also to provide an early code of eyehand coordination. Although essential for any form of reaching, eye-hand coordination has surprisingly been absent from most coding scheme for reaching so far advanced. A similar alignment of eye and hand signals was later reported in PMd (Pesaran et al., 2006; Batista et al., 2007), to which area PEc projects. The latter study showed reach cell encoding in eye-centered, limb-centered, and mixed eye-limb coordinates but could not dissociate intrinsic from extrinsic representations of reaching.

This brief and selective account of some representative coding schemes proposed for reaching in our view reflects the multiplicity and heterogeneity of reach representations in the cerebral cortex. Based on behavioral studies in humans, McGuire and Sabes (2009) have rejected the hypothesis of the existence of a unique representation suggesting that, instead, "the presence of multiple reference frames allows for optimal use of available sensory information and explains task-dependent reweighting of sensory signals" (Sabes, 2000). The latter are noisy, making it optimal to encode motor intentions simultaneously in multiple reference frames (Sabes, 2011). Recent analysis confirms the existence of coding schemes for reaching based on multiple (Bosco 
A PARIETAL

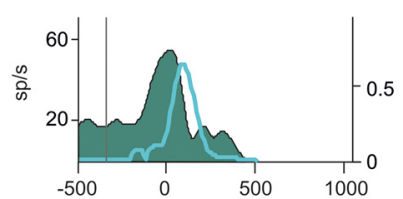

B PARIETAL
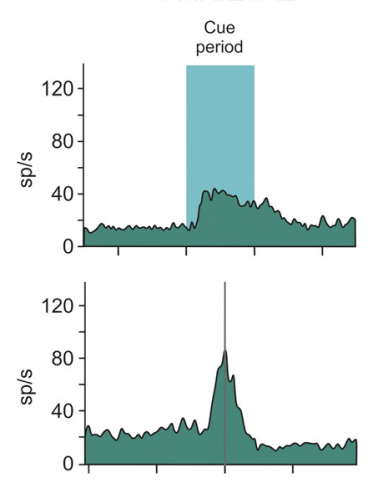

PREMOTOR

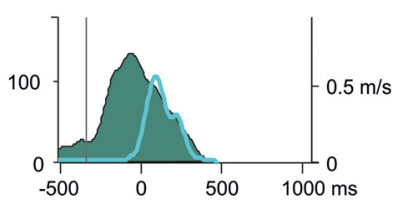

PREFRONTAL

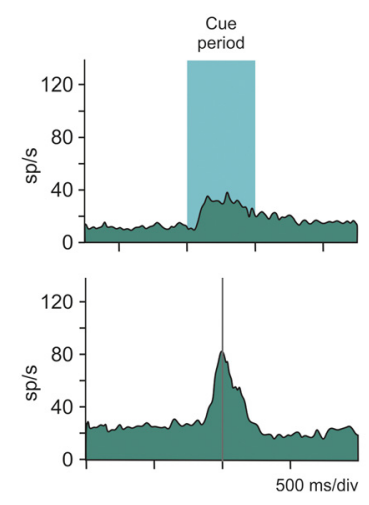

Figure 3. Neural activity types in the posterior parietal, premotor, and PFC of macaque monkeys. $A$, Spike density functions (solid green curve, in spike/seconds) of a superior parietal (PEc) and of a dorsal premotor (F2) cell studied during hand reaching to visual targets in 3D space and aligned to the onset ( $0 \mathrm{~ms}$ ) of hand movement, as determined from the hand velocity profile (light-blue curve; hand speed values shown on the right ordinate). Vertical solid gray line indicates the instant of target presentation. In both examples, the modulation of cell activity leads the hand movement onset. Data from Archambault et al. (2009) and Archambault et al. (2011). B, Population activity in the inferior parietal cortex (area 7ip/LIP) and in the PFC (area 8a) shows phasic cue-related activity (delimited by the light-blue vertical shading; top panels) and saccade-related activity (bottom panels) recorded during an oculomotor spatial memory task (the solid gray vertical line indicates the saccade onset). Data from Chafee and GoldmanRakic (1998). Notice the similarity of activation profiles between superior parietal and dorsal premotor cells $(\boldsymbol{A})$, as well as between inferior parietal and prefrontal cells $(\boldsymbol{B})$.

et al., 2015) or mixed eye-hand representations (Piserchia et al., 2017).

On a related issue, Gail et al. (2009) have proposed a preferential role of PRR neurons in encoding motor goals based on sensory-driven transformation, compared with the recruitment of PMd cells in encoding rule-based motor goals, which is consistent with the general role of premotor and PPC in motor control (Wise et al., 1997).

In the LGS, simultaneous recording from AIP, F5, and M1 has shown the differing roles of these areas in transforming visually derived object properties, such as geometry, into the hand shape appropriate for successful grasping (Schaffelhofer and Scherberger, 2016). Consistent with their position in the parietofrontal gradient, AIP is mostly concerned with the analysis of visual objects' features and shapes, to be converted by F5 into plans for hand action.

Overall, these results confirm the existence of multiple levels of representation of reaching in the parietofrontal system (Battaglia-Mayer et al., 2003), as suggested by the functional properties of neurons, by the nature of cortical connectivity, and by the consequences of parietal lesions.

\section{Timing of activation relative to behavioral events}

Another interesting question concerns the onset time of cell activity relative to hand movement. In general, neural activity is earlier in M1 than in anterodorsal area 5, despite the similarity of directional tuning properties of their reach-related neurons
(Kalaska et al., 1983). This original observation was extended by studies of M1, PMd, and PE/PEc, concerning online correction of hand trajectory (Archambault et al., 2009, 2011). Under these conditions, the time lags of neural activity relative to hand kinematics show an orderly recruitment of motor (M1), premotor (PMd), and PPC (PEa/PEc) cells. The change of target location promotes a change of motor plan earlier in PMd than in M1 and $\mathrm{PE} / \mathrm{PEC}$. Thus, PMd provides an early signaling concerning the change of task demands, M1 plays a direct and early role in the control of hand kinematics on an ongoing basis, and the PPC offers a current state estimate of the motor periphery, within a process where original and new motor intentions coexist. In a similar fashion, during reach and antireach tasks associated with partial precuing, neural activity is earlier in PMd than in PRR only when the task contingencies impose a spatial remapping of a congruent into a noncongruent spatial representation of the reach goal (Westendorff et al., 2010).

A study (Michaels et al., 2015) performed under the perspective of the neural state space hypothesis (Churchland et al., 2006) shows that, during movement preparation, population activity in F5 predicts the reaction time better than in AIP, suggesting that, within the LGS, the latter is more closely related to the motor intention and the former to the analysis of movement variability and timing.

From this brief overview, it can be safely concluded that the relationships between onset time of neural activity and hand movement are variable and task-dependent, even within a single area of the network.

\section{Functional connectivity and information transfer}

The study of functional connectivity requires simultaneous recording of neural activity across different areas. In PMd and PRR, spike-local field potential correlations are task-dependent because they are greater when monkeys made free choices than after an instruction is available to them (Pesaran et al., 2008). This decision network recruits selected subpopulations of neurons in both areas for mutual information transfer in the low-frequency $(15 \mathrm{~Hz})$ domain. Neural activity relative to behavioral events is earlier in PMd than in PPC, assigning to the former a pivotal role in driving this recurrent circuit.

Simultaneous recording of neural activity in the three cortical nodes (AIP, F5, and MI) of the LGS (Fig. 5) (Dann et al., 2016), when monkeys grasped a handle with a precision or power grip, has shown the recruitment of a network consisting, in each area, in subpopulations of neurons forming modules strongly connected across them, as in small-world architectures (Watts and Strogatz, 1998). Network functions were dominated by assemblies forming interconnected hubs, as in a rich-club topology, and characterized by cells rhythmically synchronized in the $\beta$ $(18-35 \mathrm{~Hz})$ or low-frequency range $(3-7 \mathrm{~Hz})$ (Fig. 5). Although corticocortical connections play a central role in the synchronization of activity within a network, these results cannot be interpreted as reflecting monosynaptic connections between the units recruited by the task. Interestingly, most units in the network had a nonoscillatory behavior. Worth mentioning is the hypothesis that the brain of schizophrenic patients might suffer from a significantly lower density of rich-clubs than control subjects (van den Heuvel et al., 2013).

\section{Canonical microcircuits for performance monitoring in the FC}

There is evidence that canonical microcircuits in the agranular FC can be different from those of sensory areas (Ninomiya et al., 2015), 
A
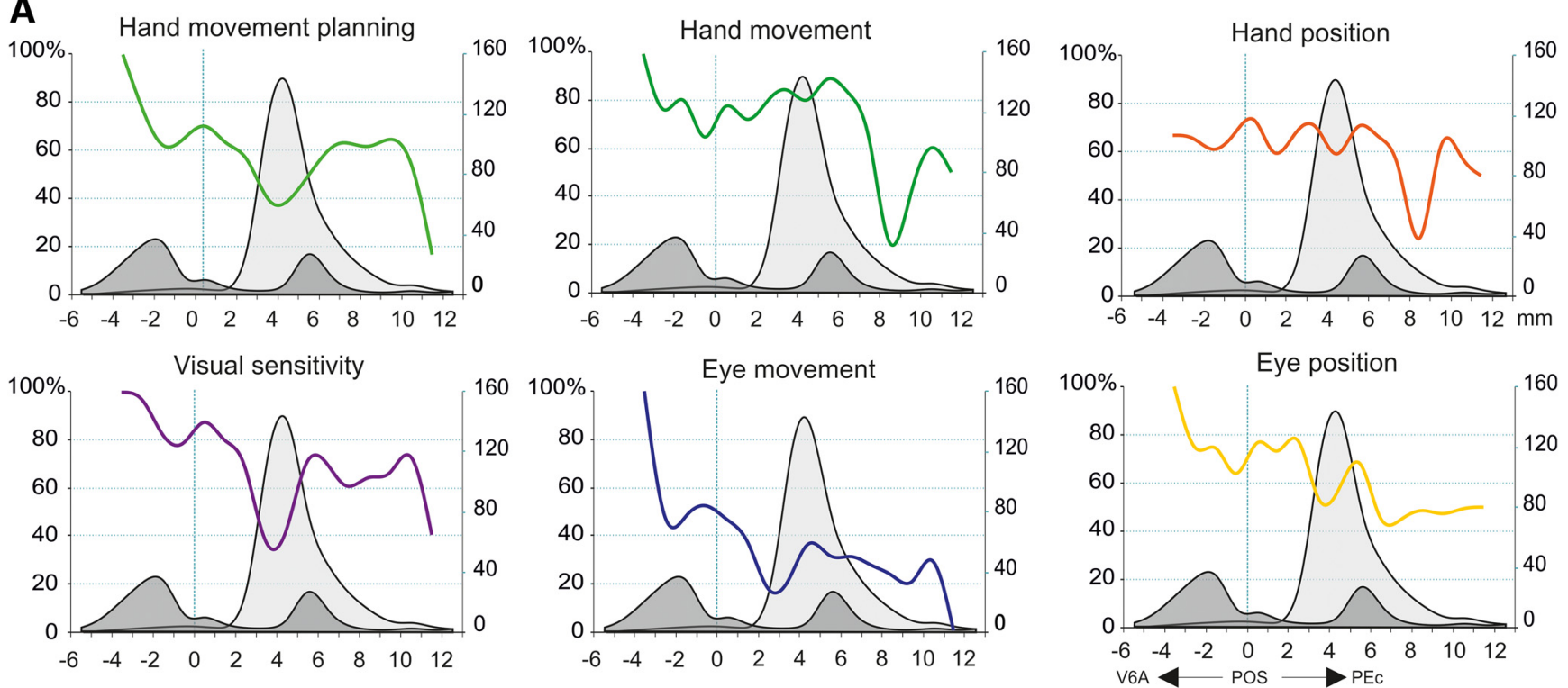

Projections to $\mathrm{F} 7$

Projections to F2

$B_{1}$

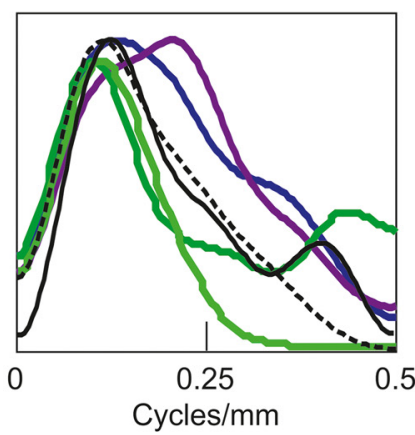

$B_{2}$

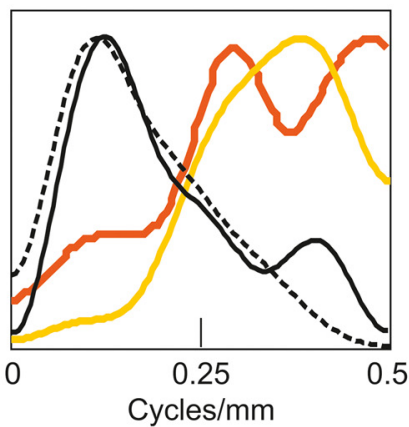

C

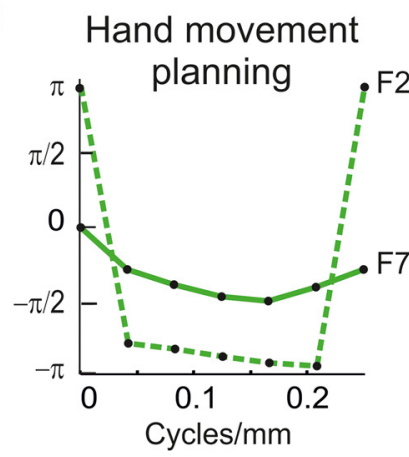

Eye movement

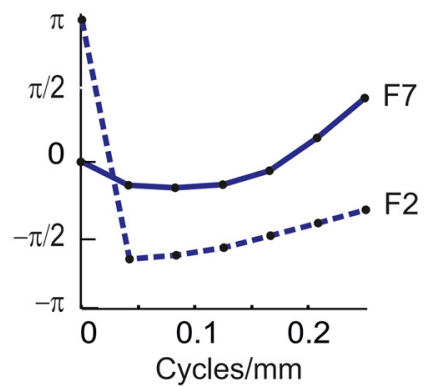

Hand movement

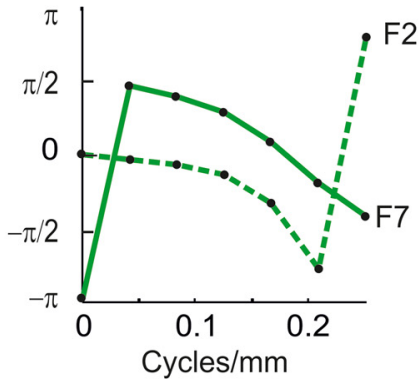

Visual

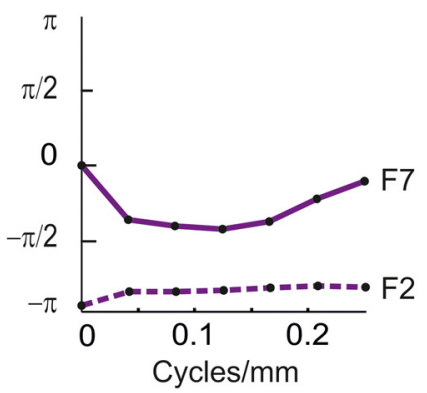

Figure 4. Comparison of the distributions of parietal activity types and parietofrontal projecting cells. A, Cell activity recorded regularly in the anteroposterior extent of the SPL of monkeys performing different tasks (reaching to foveal targets, reaching to extrafoveal targets, instructed-delay reaching, saccade) allowed the study of the distributions of cells (left ordinate) significantly modulated by planning (green), and execution (dark green) of hand movement, hand position (orange), visual target presentation (purple), eye movement (blue) and position (yellow). At the end of recording, different retrograde tracers were injected in areas $F 7$ and $F 2$ to map the distribution of parietofrontal projecting cells (right ordinate). In each graph, the distribution of cells with a given functional property is superimposed to those of parietofrontal cells projecting to F7 (dark gray) and F2 (light gray). On the abscissa, the anteroposterior extent of parietal cortex encompasses areas V6A (negative values) and PEc (positive values), with $0 \mathrm{~mm}$ corresponding to the middle of the crown of the parieto-occipital sulcus (P0S; see also Fig. 1). B, C, Quantitative relations between the spatial distributions of functional and anatomical properties described above studied along the anteroposterior dimension of SPL through a Fourier analysis. $\boldsymbol{B}_{1}$, The spectra of visual, hand movement planning/execution and eye movement signals (colored curves, as in $\boldsymbol{A}$ ), as those of the parietal cells projecting to $\mathrm{F} 7$ (dashed black) and F2 (solid black) show peaks at 0.1 cycles/mm, therefore in the low-frequency range, corresponding to a periodicity in the arrangement of cells in 5 -mm-wide bands. $\boldsymbol{B}_{2}$, The power spectra associated to eye (yellow) and hand (orange) position signals show instead peaks in the high-frequency range $(>0.25$ cycles $/ \mathrm{mm})$, indicating a more uniform distribution, in microstructures $1.5 \mathrm{~mm}$ wide, reminiscent of a columnar organization. $C$, Phase relationships, obtained from spectral analysis as a function of Fourier frequencies (cycles $/ \mathrm{mm}$ ), comparing the distributions of each functional signal and that of parietal cells projecting to $\mathrm{F} 7$ (dashed line) and F2 (solid line). The phase values are reported in the $0-0.25$ cycles $/ \mathrm{mm}$ range in which the distributions tended to be similar (i.e., in most instances with a coherency $\geq 0.8$; data not shown). Neurons related to visual, eye movement, and hand movement planning signals are in phase with cells projecting to $\mathrm{F} 7$. Hand movement-related signals were instead mainly in phase with cells projecting to F2. Modified with permission from Battaglia-Mayer et al. (2001). 

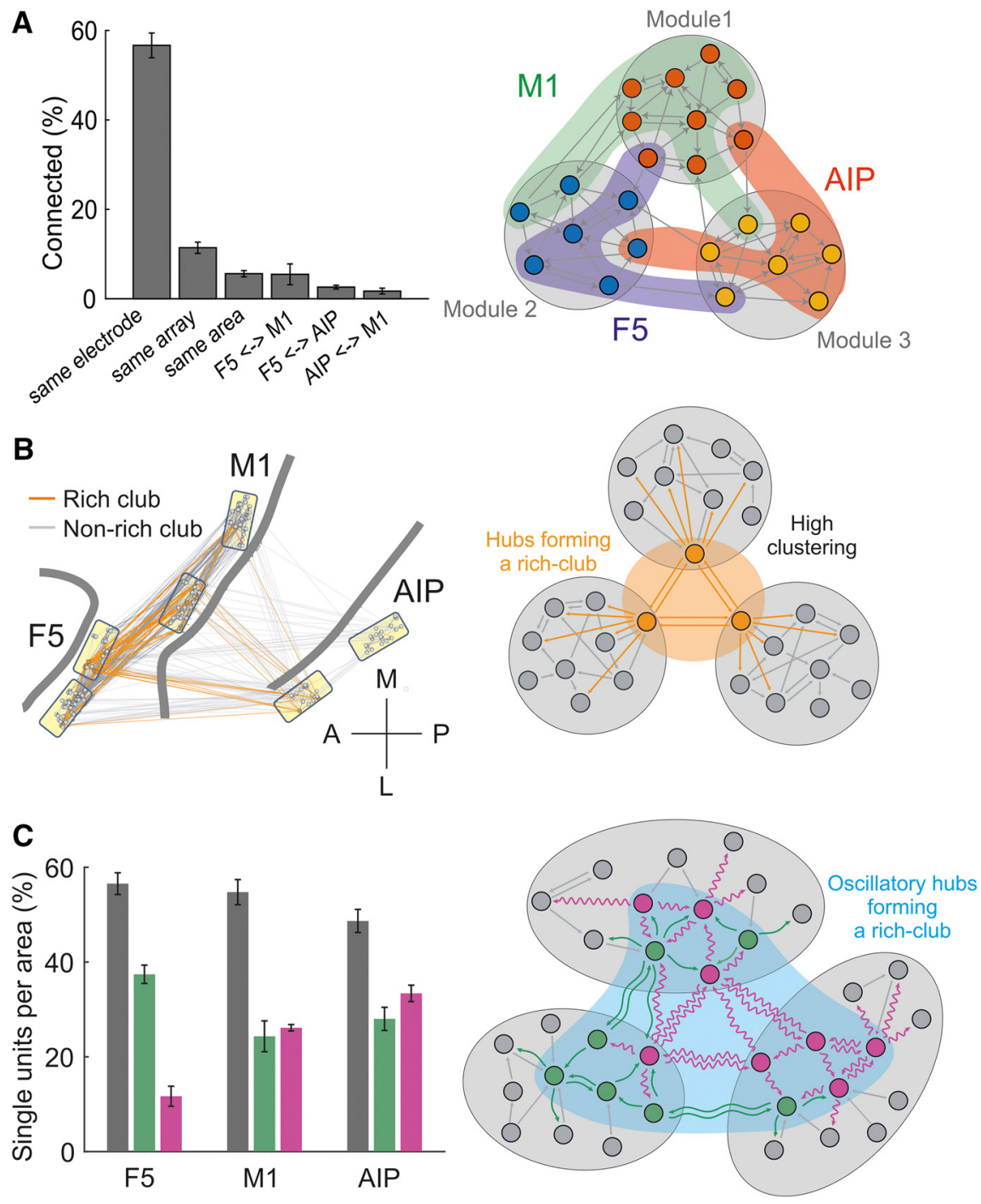

Figure 5. Functional connectivity within the LGS. Organization of single-cell network studied with cross-correlation analysis. Cell activity was recorded simultaneously from areas AIP, F5, and M1 (Fig. 1), with six multielectrode arrays (two in each area, $\boldsymbol{B}$, left), while monkeys performed different grasp actions. $\boldsymbol{A}$, Modular topology. Left, Functional connectivity among neurons decays as their tangential distance in the network increases; therefore, it is maximal from neurons whose signs of neural activity are recorded in the same location (same electrode), and progressively decreases for neurons recorded within the same array (rectangles in $\boldsymbol{B}$ ), within the same area, between F5 and M1, F5 and AIP, and AIP and MI. Right, Functional modules consist of single units from the same area and include fewer neurons from other areas. Network units have a dense local clustering and are connected to the other units via short average path length, as typical of small-world topology. B, Left, Anatomical layout of the network, displayed as a web where a small number of strongly embedded nodes display a high degree of centrality forming hubs (right), which make a strong contribution to network functions. Hubs exhibit a strong tendency to be connected to each other, forming a rich-club containing neurons from all areas, which facilitates efficient interareal communication. $\boldsymbol{C}$, Network topology of oscillators. Left, Distribution of oscillators in different areas. Green bars represent units oscillating in synchrony in the low frequency (3-7 $\mathrm{Hz})$. Pink bars represent units oscillating in synchrony in the $\beta(18-35 \mathrm{~Hz})$ bands. Grey represents nonoscillatory units. F5 displays less $\beta$ and more low-frequency oscillators than M1 and AIP. Right, The network topology of oscillators is characterized by hubs forming a rich-club (light-blue shading), where units between areas communicate in the $\beta$ (green) and low-frequency (pink) bands. Nonoscillatory units predominates in each area. Modified with permission from Dann et al. (2016).

as now confirmed by an elegant laminar analysis of the supplementary eye field of macaques performing a stop-signal countermanding saccade task (Sajad et al., 2019). By recording both cell spiking activity and error-related negativity in different laminae, this study revealed how different performance monitoring signals, such as error and reward loss and gain, can stem and flow through the different layers where they are preferentially encoded, giving rise to the error-related negativity. This suggests that, beyond anterior cingulate cortex, the frontal eye field is one source of this monitoring signal.

\section{Synaptic mechanisms of bimodal and sensory-motor integration in the parietofrontal system}

In primates, the synaptic mechanisms underlying sensory-motor integration and transformation for reaching remain to be elucidated. Data on bimodal integration are available from rodent studies. In the mouse parietal area RL (Wang and Burkhalter, 2007; Wang et al., 2012), the combination of visual (from V1) and somatosensory (from S1) signals (Olcese et al., 2013) occurs in an optimal fashion in pyramidal cells of layers II-III. This integration depends on the permissive role of parvalbumin-positive interneurons, whose optogenetic activation impairs the operations of supragranular cells, to which they project monosynaptically (Packer and Yuste, 2011). The projections of the parietal cortex to the whisker and eye motor areas (Wang et al., 2012) resemble those of monkeys.

Downstream of the parietal cortex, a direct ipsilateral connection links the S1 barrel field and the vibrissal M1 (Mao et al., 2011). Whisker deflection produces ascending volleys that first activate stellate cells in S1 layer IV. These excite pyramidal cells in layers II-III, which in turn generate a feedforward excitation of cells in layer Va and Vb (Weiler et al., 2008). Selected populations of S1 excitatory pyramids from layers II-III and Va project to the same layers and cell types in M1 (Farkas et al., 1999; Kleinfeld et al., 2002; Ferezou et al., 2007; Yamashita et al., 2018), giving rise to a reciprocal and topographically organized (Aronoff et al., 2010) recursive network. Time coincidence strengthens the synaptic efficacy of inputs arriving in S1 from the somatosensory periphery and from M1 (Xu et al., 2012), promoting LTP.

It has been suggested that the synaptic integration of somatosensory signals about whisker deflection and motor outflow about whisking allow the computation of object location in space. Calcium imaging of the M1-S1 projections in layer I shows the existence of intermingled axons with activity patterns related to whisker movement, touch, and object location (Petreanu et al., 2012), which confirms the important role of $\mathrm{M} 1$ in somatosensory processing (Mountcastle, 2005).

Extrapolated to primates, where the PPC is significantly expanded relative to rodents (Orban et al., 2006; Peeters et al., 2009; Caminiti et al., 2015; Kaas et al., 2018), similarly arranged S1-M1 corticocortical and intracortical circuits, rather than object loca- 
tion in space, probably subserve somatosensory control of hand movement. Indeed, S1 lesion in primates does not impair the coordinate-transformation for target localization in space, which results in optic ataxia after parietal lesion, but rather the sensory control of hand action, which affects stereognosis, that is, the haptic appreciation of the 3D form of object (Mountcastle, 2005). Therefore, evolution has probably assigned the functions that in rodents are confined to the S1-M1 circuit to an expanded parietal network (Caminiti et al., 2015; Borra and Luppino, 2018).

Encoding of whisker-dependent somatosensory discrimination undergoes cross-modal plasticity because it is significantly modified by visual deprivation early in life. This form of plasticity enhances the selectivity of S1 neurons and improves decoding of stimulus position (Ramamurthy and Krubitzer, 2018).

Finally, at the early stages of composition of coordinated eye-hand movements underlying reaching, single-cell activity in parietal area V6A, 7m, and PEc is influenced by visual, eye, and hand signals, which are all integrated in a directionally congruent fashion within the global tuning field of individual cells (BattagliaMayer et al., 2000, 2001). A network model (Mascaro et al., 2003) shows that the global tuning field emerges by combining inputs about the retinal target position, hand position, and eye position. Cross-modal Hebbian interactions generated by experience account for natural correlations between the preferred directions of these signals. In a recurrent scenario, when inhibition is locally suppressed, the global tuning field of individual neurons no longer emerges, leading to the collapse of signal integration and, potentially, to optic ataxia (BattagliaMayer and Caminiti, 2002). Consistent with this, modeling studies (Asher et al., 2015) of the DRS show that intrinsic lateral connections within PPC are essential for the composition of accurate reaches with smooth trajectory and velocity profiles, such as those of observed in primates.

\section{Corticocortical connections and motor skill learning}

Skill learning consists in the ability to perform actions with increasing speed and overall accuracy greater than in prelearning conditions (Shmuelof and Krakauer, 2011). In mouse MI, skill learning strengthens horizontal connections (Rioult-Pedotti et al., 1998) by promoting LTP (Keller et al., 1991; Rioult-Pedotti et al., 2000; see Sanes and Donoghue, 2000), as in cats (Iriki et al., 1989). Long-lasting optical imaging of layer II-III neurons in M1 shows that learning-dependent plasticity rests on changes in the correlated activity of nearby neurons thanks to horizontal connections, as well as on training progression over time and behavioral sessions (Komiyama et al., 2010). During learning, cells in layer Va modulate their circuit activity to reflect the status of the motor periphery, such as limb position (Masamizu et al., 2014). When mice learn to use the whiskers to detect objects and report detection by licking, pyramidal cells in layers II-III show a flexible

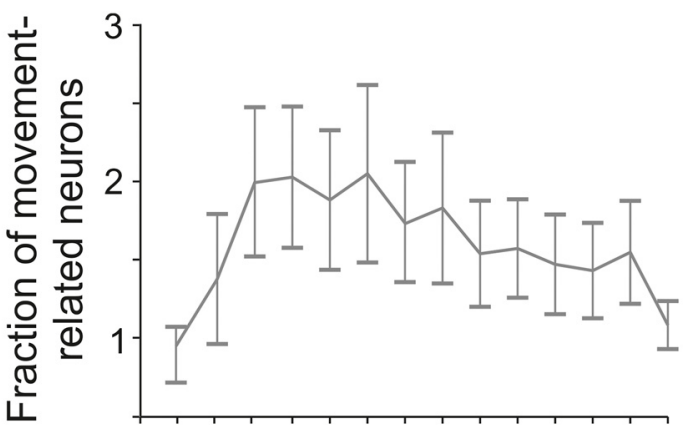

Figure 6. Dynamics of motor learning in mouse motor cortex. Mean proportion of excitatory movement-related neurons recruited during motor learning of a forelimb lever-press task obtained from two-photon calcium imaging of mouse motor cortex er 2 weeks. Notice the initial increase in the number of cortical neurons recruited by the task, implying an expansion of the ollowed by their partial elimination, as well as the similar time course of neural assembly and spine dynamics during learning. Modified with permission from Peters et al. (2014).

association between sensory input and motor output (Huber et al., 2012) because the representation of whisking remains stable over time, whereas that of licking strengthens as a function of the behavioral performance. At the population level, motor learning in M1 induces a dynamic expansion and reshaping of neural assemblies to achieve reproducible activity patterns coincident with a transient increase in the turnover of dendritic spines of neurons within these assemblies (Fig. 6) (Peters et al., 2014), as also shown by previous studies (Xu et al., 2009; Yang et al., 2009).

Inhibitory circuits play a major role in M1 during skill learning (Chen et al., 2015), which in layer I induces a reorganization of the spines of the apical dendrites of excitatory cells of layers II-III. This reorganization is paralleled by a concomitant process involving local inhibitory circuits. Indeed, somatostatin-expressing inhibitory interneurons play a pivotal role in learning-dependent changes of excitatory synapses, given that their optogenetic manipulation impairs skill acquisition. This class of interneurons provides tonic inhibition of the apical dendrites of pyramidal neurons, which receive afferent cortical information (Gentet et al., 2012) and can flexibly adjust the efficacy of long-range inputs during motor learning.

Thalamic afferents arriving on M1 cells from the body part that they control, during training, undergo LTP and therefore use-dependent potentiation (Biane et al., 2016). Motor learning is influenced by the core systems of the brainstem because depriving M1 of dopaminergic afferents abolishes skill acquisition (Hosp et al., 2011), implying that skill learning occurs in M1. 
During development and motor learning, the acquisition of a new skill by M1 tends to confer robustness to the motor output, as suggested by experimental results and network modeling of M1 population dynamics during reaching in monkeys (Russo et al., 2018).

The studies discussed above can be regarded as cellular and circuit mechanisms of motor learning described in motor, premotor, and parietal areas in monkeys (Wise et al., 1998; Li et al., 2001; Padoa-Schioppa et al., 2004; Rokni et al., 2007). For example, in M1, PMd, and PMv, associative visuomotor learning promotes the acquisition and consolidation of new visual properties of neurons (Zach et al., 2008).

Conditional motor learning based on arbitrary associations between sensory stimuli and motor responses critically depends on a distributed system, including PMd (Wise et al., 1997), PFC (Asaad et al., 1998), hippocampus, and striatum (Petrides, 1982, 1985; Wise and Murray, 1999, 2000; Gaffan and Harrison, 1988, 1989; Toni and Passingham, 1999; for a recent review, see Makino et al., 2016). The interplay between learning-dependent and learning-selective activity, the former increasing and the latter decreasing during learning, occurs in a graded fashion across different nodes (Mitz et al., 1991; Cahusac et al., 1993; Chen and Wise, 1996, 1997; Asaad et al., 1998; Tremblay et al., 1998; Xiang and Brown, 1999), whose roles are congruent with the consequences of their lesion (for review, see Wise and Murray, 2000). This process involves early formation of arbitrary associations in the striatum, monitoring training evolution by PFC (Pasupathy and Miller, 2005), and long-term memory storage or recall of new associations in the hippocampus.

In the PPC, learning tool use modifies the functional properties of neurons (Iriki et al., 1996; Obayashi et al., 2000), interpreted as an extension of the subjective body image, which would incorporate the tool. This process seems to be accompanied by the expansion of the terminal arbors of corticocortical afferents (Hihara et al., 2006) to the PPC.

In the inferior parietal lobule areas PFG/PF (Ferrari-Toniolo et al., 2015), neural activity is modulated by hand force application on a joystick; and when a new force condition is presented, requiring the monkeys to rescale the force output, the activity of a consistent population of parietal neurons is modulated by the new task dynamics. At the end of a "wash-out" session, which returns the force output to the preperturbation condition, cell activity does not return to the baseline but retains traces of the learned association, a process that probably serves as a memory reservoir for the control of future hand force output.

Thus, the operations of the parietofrontal system largely depend on information provided by corticocortical connections that link parietal and frontal areas with similar activity types or functional modules across areas where neurons show oscillatory activity, whereas most of them communicate in a nonoscillatory fashion. It is our hypothesis that this arrangement probably depends on motor learning, which could shape dedicated experience-dependent networks for eye and hand actions during postnatal acquisition and consolidation of motor skills. Therefore, corticocortical connections probably carry inputs that instruct learning-dependent circuits formed across cortical areas by functional modules sharing properties essential for the network's dynamics. Such modules are continuously accessible to new environmental information. Therefore, corticocortical connections are a natural substrate for motor learning and for behavioral- and use-dependent changes of cortical circuits, factors that altogether improve action accuracy and control.

Motor learning seems to occur in different forms at different nodes of distributed cortical and subcortical systems (Sanes and
Donoghue, 2000), that is, in an unsupervised Hebbian fashion in the cerebral cortex (Mascaro et al., 2003), in the form of reinforcement learning (Lee et al., 2012) in the basal ganglia, and error-based learning (Wolpert et al., 2011) in the cerebellum (Bostan and Strick, 2018). All these structures participate in different stages, which include also information transfer through the topographically organized direct subcortical connections between basal ganglia and cerebellum (Hoshi et al., 2005; Bostan and Strick, 2018). In humans (Fermin et al., 2016), different nodes of such distributed systems seem to underpin distinct learning strategies. Over recent years, comprehensive treatments of different aspects of sensorimotor learning have been provided previously (Shmuelof and Krakauer, 2011; Makino et al., 2016; Bostan and Strick, 2018).

Regardless of the neural center involved, during motor learning, newly formed memories could interfere with old ones. A new study (Sheahan et al., 2016) in humans shows that motor memories can only be separated during motor preparation, rather than during motor execution, consistent with the idea that they are associated with different neural states (for a commentary, see O'Shea and Shenoy, 2016).

\section{Inhibition in motor control}

The distributed system for inhibitory control of action must be elaborate and flexible enough to subserve different action contexts, individual differences and genetic variations (Mione et al., 2015). The cerebral cortex contains several types of pyramidal cells in layers II-III and V-VI, and their characteristics depend on the cortical layer, area, and species (van Aerde and Feldmeyer, 2015; Gilman et al., 2017; Luebke, 2017). In addition, 15 classes of interneurons (Jiang et al., 2015) are available for shaping cortical circuit functions.

The role of inhibition in motor control has been discussed since early studies showed that local recurrent inhibition sharpens the focus of spatial excitation in M1 (Stefanis and Jasper, 1964). Today, inhibition is considered important for shaping the directional tuning profile of reach-related neurons (Georgopoulos and Stefanis, 2007; Mahan and Georgopoulos, 2013), on which both reach direction and accuracy might depend (Georgopoulos and Carpenter, 2015).

Motor preparation can be characterized by neural dynamics that incorporate selective suppression of neural assemblies. In mice, during a delayed Go/No-Go reaching task, movement preparation rests on the selective suppression of a subset of layer II-III cells (Hasegawa et al., 2017), which account for the animal's reaction time. In humans, it is accompanied by the selective inhibition of local circuits that facilitate, rather than suppress, the preparation of fast movements (Hannah et al., 2018).

During the instructed suppression of reaches (Mirabella et al., 2011; Mattia et al., 2013; for review, see Battaglia-Mayer et al., 2014), the M1 output is probably under the control of local interneurons (Reynolds and Ashby, 1999). Indeed, the premotor areas contributing to the corticospinal system are reciprocally connected to $\mathrm{M} 1$ and can gate movement generation by targeting M1 interneurons through a feedforward inhibition (Ghosh and Porter, 1988; Tokuno and Nambu, 2000). Furthermore, fast pyramidal tract neurons of layer $\mathrm{V}$ could target inhibitory interneurons in the spinal cord (Dum and Strick, 1991), thus gating the efficacy of M1 descending volleys. A gating role of PMd over M1 is supported by injections of the GABA-A antagonist muscimol in PMd, which reduces the ability of monkeys to withhold movements (Sawaguchi et al., 1996), as well as by PMd lesion, which results in a pathological frequency of uncontrolled arm move- 
ments (Moll and Kuypers, 1977). During reach inhibition, different PMd populations with preparatory activity display either a reduction or an increase in their firing rate (Mirabella et al., 2011), which is compatible with both scenarios mentioned above, as well as with the Boucher et al. (2007) version of the interactive race model, where stop and go processes are viewed as nonindependent mechanisms.

It could be hypothesized that, when a movement is to be suppressed, PMd neurons targeting inhibitory interneurons in the spinal cord increase their activity, whereas those targeting M1 will reduce it. It remains to be determined whether the control gate is located at the cortical and/or subcortical level. Withholding a movement during a delay period facilitates the activity of corticomotoneuronal cells, while suppressing that of pyramidal tract neurons (Soteropoulos, 2018). A fraction of the latter display firing patterns typical of inhibitory cells and could therefore participate in action suppression. A late gating influence can still be exerted in the spinal cord, where descending inputs can influence spinal inhibitory circuits (Prut and Fetz, 1999). Similarly, a gating-based mechanism for the corticocortical influence over the output of M1 requires circuit analysis. Regardless of the nature of descending commands, the Renshaw cells in the spinal cord will contribute by suppressing the excitatory fringe surrounding motoneuronal pool excitation (Renshaw, 1941; Hultborn et al., 1979). Concerning topography, behavioral studies support the existence of a common mechanisms of inhibitory control for the finger, wrist, and arm movement (Brunamonti et al., 2012).

At variance from the gating hypothesis, the dynamical systems approach (Churchland et al., 2010; Elsayed et al., 2016) holds that motor intention evolves into movement generation because of a change of state in the interactions occurring within a population of cortical neurons and does not necessarily depend on the subthreshold activation or direct inhibition of neural groups. In the "output-null hypothesis" (Kaufman et al., 2014), PMd signaling can attenuate neural activity in M1 by selectively adopting an "output-null" rather than an "output-potent" pattern of activity, with the consequence of reducing or halting the communication between PMd and M1, therefore between them and the spinal cord. How this transition between different output states emerges from cell interactions in the network remains a major challenge for future investigation. This topic can also be relevant to the question of how motor intentions can switch the operation mode of cortical networks.

\section{Role of the thalamus in corticocortical communication}

Cortical areas project from layer V and VI descending axons (CTh) of different morphologies and degrees of convergence to the thalamic nuclei from which they receive afferent information (Rockland, 2019). These projections represent an evolutionary specialization of mammals because they are absent in reptiles (Pritz, 1995) and are often collaterals of axons for the midbrain and other subcortical centers (Guillery, 1995; Guillery and Sherman, 2002; Shermann, 2016, 2017). The latter receive the same messages addressed to the thalamus and, through it, to other cortical areas. Therefore, the CTh pathways would not only exert a modulatory effect on thalamocortical inflow but also on the activity of higher-order areas through trans-thalamic loops (TThL).

The CTh projections from parietal areas $\mathrm{PE}$ and $\mathrm{PEa}$ in monkeys obey to this pattern because they terminate, not only on portions of the n. LP that project back to PE/PEa, but also on LP territories projecting to PMd (Cappe et al., 2009). Therefore,
$\mathrm{PE} / \mathrm{PEa}$, in addition to their direct frontal projections, can use a TThL to address sensory-motor signals to PMd. This system is reciprocal, like most corticocortical ones. The conduction delays of this and other TThL routes are unknown and should be contrasted to those involved in the direct SPL-PMd and SPL-M1 projections, which are on average 3.3 and $1.9 \mathrm{~ms}$, respectively. This direct system seems to be faster than the related TThL, if one only considers that in monkeys the M1 to VL (n. ventralis lateralis) projection, which is just one segment of the TThL discussed above, accumulates transmission delays of $\sim 3.52-3.87 \mathrm{~ms}$ (Tomasi et al., 2012). This implies that the signals traveling through direct association connections and through TThL impinge on premotor or parietal neurons at different times and in a temporally dispersed fashion. Elucidating this interplay will be essential for understanding the temporal dynamics of thalamic influences on corticocortical communication. The CTh influence is taskdependent because, during low-frequency activity, it is suppressive, whereas it is enhancing during high-frequency activity (Crandall et al., 2015); it depends on short-term plasticity of dynamic synapses and might serve different behavioral demands.

Beyond the influence on cortical dynamics, communication within and between sensory and motor centers accumulates transmission delays, which, together with decision delays, must be compensated, especially when movement correction is required. This process can occur centrally, through forward models (Wolpert and Miall, 1996), that predict by implicit knowledge the sensory consequence of forthcoming actions.

Rikhye et al. (2018b) have advanced the view that the thalamus is central to cognitive functions by acting as a Bayesian observer for forward models based on contextual information, therefore important to instruct and update the cortex on modifications of task-relevant events. This can be achieved by strengthening the effective connectivity between cortical cells. This view confers to the thalamus a role in cortical communication and cognition, as suggested by the existence of important differences in the functional properties of thalamic cells and of cortical neurons to which they project. As an example, these authors cite the monkey's pulvinar, where neural activity reflects the subjective confidence in perceptual evaluations (Komura et al., 2013), rather than the perceptual category encoded in PPC (Kiani and Shadlen, 2009) to which the pulvinar projects. In mice, the nucleus medialis dorsalis (MD) contains neurons retaining in memory rules-based information relevant to attention, without relaying categorical information to PFC (Schmitt et al., 2017). In the same vein, a new study (Rikhye et al., 2018a) shows that MD participates in switching PFC neural representations of cues that instruct the allocation of attention to different targets, which implies a role for the thalamus in cognitive flexibility, which is severely disturbed in schizophrenia and other mental disorders.

An elegant new study in rats (Yang et al., 2019) concerning the network mechanisms of declarative memory consolidation has shown that MD can modulate the functional connectivity between medial PFC and hippocampus because, in the awake state, its activity is suppressed during hippocampal ripples. During nonREM sleep, MD activity is upregulated in coincidence with spindlecoupled ripples and downregulated when ripples are uncoupled with sleep spindles. While this suppression of MD activity can facilitate the memory consolidation by reducing the influence of sensory stimuli, therefore the MD relay operation mode, MD input can help sharpening the communication between hippocampus and medial PFC, thanks to the spindle-ripple coupling.

In conclusion, the MD-PFC relations offer an ideal circuit to study thalamic influences on cortical communications and their 
role in cognition, as now suggested by many studies. Comprehensive reviews on the role of the thalamus in cognition are now available (Rikhye et al., 2018b; Wolff and Vann, 2019).

\section{Cortical connections and distant effects of brain lesions: diaschisis and homeostatic regulation of neural circuits}

Deciding the functional roles of a cortical area and of its corticofugal systems from their lesion or transient inactivation can be fallacious because these affect the operations of all afferent and efferent cortical pathways and therefore of many distributed systems. Lesions produce distant effects, classically referred to as diaschisis (Carrera and Tononi, 2014). In neurology, the immediate postlesion symptomatology often changes over time with partial or full recovery of function. In monkeys, the short-term acute effects of selective inactivation or lesions are different from their long-term chronic consequences, as shown, for example, in the hand dominant domain of parietal cortex (area PE, PEa, MIP) (Padberg et al., 2010), M1 (Darling et al., 2011), pulvinar (Bender and Baizer, 1990; Wilke et al., 2010), area MT (Newsome and Paré, 1988), and in the auditory cortex in rodents (Talwar et al., 2001). This is true also for the effects of short-term optogenetic silencing (for a critical commentary, see Pratt and Prather, 2016).

To tackle this issue, an elegant study (Otchy et al., 2015) has shown that muscimol injection into the M1 of rats and in the nucleus interfacialis (Nif) of zebra finches degrades a learned sequence of forelimb lever presses in the former, courtship songs in the latter. This scenario differs from that observed after a permanent lesion, which is accompanied by a significant recovery of functions in both species. In zebra finches, taken as model, recovery is consistent with postlesion changes occurring in the high vocal center, a downstream structure that receives excitatory input from Nif and controls song timing. The gradual recovery of function can be interpreted within the frame of the homeostatic regulation of neural activity within cortical circuits (Turrigiano, 1999; Marder and Goaillard, 2006; Keck et al., 2013).

In NHPs, both the corticospinal and the reticulospinal systems influence the hand motoneurons, and the former's input is stronger than that of the latter (Zaaimi et al., 2012). At about 6 months after the unilateral section of the pyramidal tract, although hand grip remains weak and independent digit movement severely impaired, the recovery of an elementary form of grasping occurs. This is paralleled by a concomitant increase of excitatory inputs to the forelimb flexors and to the intrinsic hand muscles, dependent on a change in the functional connectivity profile of the corticoreticular pathway, which is upregulated. Impressive changes of cortical excitability after lesion is a common observation in different animal species and in humans and can provide potential substrates for recovery of functions.

The above studies indicate that intact motor cortex is necessary for the expression of the learned motor behaviors but not to encode the full complexity of learned sequences and memories: in other words, for learning novel motor skills but not for their execution after learning is completed. This conclusion was also reached by Kawai et al. (2015), who have shown that M1 lesion has no consequences on acquired skills not based on dexterity but makes animals unable to acquire new ones.

Therefore, M1 seems to have a permissive role in learned behavior and an instructive one in the early acquisition of new skills and in orchestrating the adaptation of subcortical motor circuits to novel task demands (Grillner and Wallén, 2004), whereby they can be stored due to neural plasticity (Sanes and Donoghue, 2000; Ungerleider et al., 2002; Dayan and Cohen, 2011).
These studies point to a "greater role for M1 in controlling an operantly conditioned movement and to a lesser role for M1 in an instinctive movement using the same muscles" (Evarts, 1981), in other words, to a higher-order role of M1 in motor cognition (Georgopoulos et al., 1993; Georgopoulos and Carpenter, 2015). Over the years, this has been shown in monkeys by the M1 involvement in mental rotation of movement direction (Georgopoulos et al., 1989), context recall (Pellizzer et al., 1995), encoding of serial order in working memory tasks (Carpenter et al., 2018), maze solution (Crowe et al., 2004b), and many other functions. Recent studies in rodents (for review, see Ebbesen et al., 2018) point in the same directions.

\section{Conclusion}

The several parietofrontal pathways emerging from the parietofrontal eye-hand matrix (Battaglia-Mayer, 2019) form the skeleton of the parietofrontal system and reveal the existence of different information streams for actions based on eye-hand coordination. This network is characterized by different entry points and outflow pathways that can be selectively recruited based on task contingencies. Population codes based on the tuning properties of neurons and on dynamical systems embedded in anatomically related frontal and parietal areas can provide accurate predictions of behavior and its modifications during task evolution. At the same time, their collapse offers tentative explanations of the deficits occurring after lesion of the potential homologs in humans.

Heterogeneity of functions, even within a single area, is therefore not surprising because it emerges in an almost obligatory fashion from such a complex anatomofunctional matrix. As an example, VIP participates in guiding locomotion, recognizing numerosity of targets for potential actions, encoding near-field approaching, or receding visual stimuli for promoting defensive behavior. This heterogeneity, which is however aimed at encoding ethologically relevant forms of behavior, is naturally enriched in humans by evolution, which has probably expanded the number of neural groups available for sensory-motor integration and for simultaneous representation of action in different reference frames.

The multiplicity of corticocortical streams is paralleled by that of the corticospinal systems, which allow parietal and frontal area areas to select their outflow routes based on task demands and to orchestrate their action on subcortical centers where they project. This function could be particularly relevant to allow these phylogenetically older structures to store and perform new motor skills. As an example, the "new M1" (Rathelot and Strick, 2009), with its privileged access to spinal motoneurons (Witham et al., 2016), the evolution of parietal areas related to hand functions (Padberg et al., 2007), and an expanded parietofrontal system (Caminiti et al., 2015) can be considered as crucial evolutionary enrichments for motor functions and cognition. Within this frame, the direct parietospinal projection (Rathelot et al., 2017; Innocenti et al., 2019) can convey to the motor output command signals (Mountcastle, 1978), as well as information relevant to other functions, such as visuomotor adaptation, that after rapid error correction return behavior to baseline performance (Shmuelof and Krakauer, 2011) and probably occurs in the parietoponto-cerebellar system. Indeed, visuomotor adaptation is unaffected in patients with stroke and scarcely impaired in Parkinson's and Huntington's diseases (Shmuelof and Krakauer, 2011).

We believe that this variety of architectures and functional motifs has enriched the motor system with the capacity to encode 
movement within different action fields and choice options with appropriate timing, also thanks to the wide range of communication delays available to corticocortical signaling. This is modulated by corticothalamic loops, which confers flexibility and state dependency to corticocortical communication and to the thalamus a role in motor cognition. Such complex networks and their interactions might serve to continuously expand and reshape the neural composition and repertoire of cortical assemblies available for motor learning and adaptation, to ultimately allow the flexible spatiotemporal tuning of daily actions.

\section{References}

Archambault PS, Caminiti R, Battaglia-Mayer A (2009) Cortical mechanisms for on-line control of hand movement trajectory: the role of the posterior parietal cortex. Cereb Cortex 19:2848-2864.

Archambault PS, Ferrari-Toniolo S, Battaglia-Mayer A (2011) Online control of hand trajectory and evolution of motor intention in the parietofrontal system. J Neurosci 31:742-752.

Aronoff R, Matyas F, Mateo C, Ciron C, Schneider B, Petersen CC (2010) Long-range connectivity of mouse primary somatosensory barrel cortex. Eur J Neurosci 31:2221-2233.

Asaad WF, Rainer G, Miller EK (1998) Neural activity in the primate prefrontal cortex during associative learning. Neuron 21:1399-1407.

Asher DE, Oros N, Krichmar JL (2015) The importance of lateral connections in the parietal cortex for generating motor plans. PLoS One 10: e0134669.

Averbeck BB, Seo M (2008) The statistical neuroanatomy of frontal networks in the macaque. PLoS Comput Biol 4: e1000050.

Averbeck BB, Battaglia-Mayer A, Guglielmo C, Caminiti R (2009) Statistical analysis of the parieto-frontal cognitive-motor network. J Neurophysiol 102:1911-1920.

Balint R (1909) Seelenlähmung des "schauens," optische ataxia, räumliche störung der aufmerksamkeit. Mschr Psychiat Neurol 25:51-66.

Batista AP, Buneo CA, Snyder LH, Andersen RA (1999) Reach plans in eyecentered coordinates. Science 285:257-260.

Batista AP, Santhanam G, Yu BM, Ryu SI, Afshar A, Shenoy KV (2007) Reference frames for reach planning in macaque dorsal premotor cortex. J Neurophysiol 98:966-983.

Battaglia-Mayer A (2019) A brief history of the encoding of hand position by the cerebral cortex: implications for motor control and cognition. Cereb Cortex 29:716-731.

Battaglia-Mayer A, Caminiti R (2002) Optic ataxia as result of the breakdown of the global tuning fields of parietal neurons. Brain 125:1-13.

Battaglia-Mayer A, Caminiti R (2018) Parieto-frontal networks for eyehand coordination and movements. Handb Clin Neurol 151:499-524.

Battaglia-Mayer A, Ferraina S, Mitsuda T, Marconi B, Genovesio A, Onorati P, Lacquaniti F, Caminiti R (2000) Early coding of reaching in the parieto-occipital cortex. J Neurophysiol 83:2374-2391.

Battaglia-Mayer A, Ferraina S, Genovesio A, Marconi B, Squatrito S, Molinari M,Lacquaniti F, Caminiti R (2001) Eye-hand coordination during reaching: II. An analysis of the relationships between visuomanual signals in parietal cortex and parieto-frontal association projections. Cereb Cortex 11:528-544.

Battaglia-Mayer A, Caminiti R, Lacquaniti F, Zago M (2003) Multiple levels of representation of reaching in the parieto-frontal network. Cereb Cortex 13:1009-1022.

Battaglia-Mayer A, Mascaro M, Brunamonti E, Caminiti R (2005) The overrepresentation of contralateral space in parietal cortex: a positive image of directional motor components of neglect? Cereb Cortex 15:514-525.

Battaglia-Mayer A, Ferrari-Toniolo S, Visco-Comandini F, Archambault PS, Saberi-Moghadam S, Caminiti R (2013) Impairment of online control of hand and eye movements in a monkey model of optic ataxia. Cereb Cortex 23:2644-2656.

Battaglia-Mayer A, Buiatti T, Caminiti R, Ferraina S, Lacquaniti F, Shallice T (2014) Correction and suppression of reaching movements in the cerebral cortex: physiological and neuropsychological aspects. Neurosci Biobehav Rev 42:232-251.

Bender DB, Baizer JS (1990) Saccadic eye movements following kainic acid lesions of the pulvinar in monkeys. Exp Brain Res 79:467-478.

Biane JS, Takashima Y, Scanziani M, Conner JM, Tuszynski MH (2016)
Thalamocortical projections onto behaviorally relevant neurons exhibit plasticity during adult motor learning. Neuron 89:1173-1179.

Borra E, Luppino G (2018) Large-scale temporo-parieto-frontal networks for motor and cognitive motor functions in the primate brain. Cortex 97:306-326.

Borra E, Gerbella M, Rozzi S, Luppino G (2017) The macaque lateral grasping network: a neural substrate for generating purposeful hand actions. Neurosci Biobehav Rev 75:65-90.

Bosco A, Breveglieri R, Reser D, Galletti C, Fattori P (2015) Multiple representation of reaching space in the medial posterior parietal area V6A. Cereb Cortex 25:1654-1667.

Bostan AC, Strick PL (2018) The basal ganglia and the cerebellum: nodes in an integrated network. Nat Rev Neurosci 19:338-350.

Boucher L, Palmeri TJ, Logan GD, Schall JD (2007) Inhibitory control in mind and brain: an interactive race model of countermanding saccades. Psychol Rev 114:376-397.

Breveglieri R, De Vitis M, Bosco A, Galletti C, Fattori P (2018) Interplay between grip and vision in the monkey medial parietal lobe. Cereb Cortex 28:2028-2042.

Britten KH (2008) Mechanisms of self-motion perception. Annu Rev Neurosci 31:389-410.

Brunamonti E, Ferraina S, Paré M (2012) Controlled movement processing: evidence for a common inhibitory control of finger, wrist, and arm movements. Neuroscience 215:69-78.

Bruni S, Giorgetti V, Bonini L, Fogassi L (2015) Processing and integration of contextual information in monkey ventrolateral prefrontal neurons during selection and execution of goal-directed manipulative actions. J Neurosci 35:11877-11890.

Bruno RM, Simons DJ (2002) Feedforward mechanisms of excitatory and inhibitory cortical receptive fields. J Neurosci 22:10966-10975.

Bufacchi RJ, Iannetti GD (2018) An action field theory of peripersonal space. Trends Cogn Sci 22:1076-1090.

Buiatti T, Skrap M, Shallice T (2013) Reaching a moveable visual target: dissociations in brain tumor patients. Brain Cogn 82:6-17.

Bullmore E, Sporns O (2009) Complex brain networks: graph theoretical analysis of structural and functional systems. Nat Rev Neurosci 10:186198.

Cahusac PM, Rolls ET, Miyashita Y, Niki H (1993) Modification of the responses of hippocampal neurons in the monkey during the learning of a conditional spatial response task. Hippocampus 3:29-42.

Cai X, Padoa-Schioppa C (2014) Contributions of orbitofrontal and lateral prefrontal cortices to economic choice and the good-to-action transformation. Neuron 81:1140-1151.

Caminiti R, Johnson PB, Urbano A (1990) Making arm movements within different parts of space: dynamic mechanisms in the primate motor cortex. J Neurosci 10:2039-2058.

Caminiti R, Johnson PB, Galli C, Ferraina S, Burnod Y (1991) Making arm movements within different parts of space: the premotor and motor cortical representation of a coordinate system for reaching to visual targets. J Neurosci 11:1182-1197.

Caminiti R, Ghaziri H, Galuske R, Hof PR, Innocenti GM (2009) Evolution amplified processing with temporally dispersed slow neuronal connectivity in primates. Proc Natl Acad Sci U S A 106:19551-19556.

Caminiti R, Carducci F, Piervincenzi C, Battaglia-Mayer A, Confalone G, Visco-Comandini F, Pantano P, Innocenti GM (2013) Diameter, length, speed, and conduction delay of callosal axons in macaque monkeys and humans: comparing data from histology and magnetic resonance imaging diffusion tractography. J Neurosci 33:14501-14511.

Caminiti R, Innocenti GM, Battaglia-Mayer A (2015) Organization and evolution of parieto-frontal processing streams in macaque monkeys and humans. Neurosci Biobehav Rev 56:73-96.

Caminiti R, Borra E, Visco-Comandini F, Battaglia-Mayer A, Averbeck B, Luppino G (2017) Computational architecture of the parieto-frontal network underlying cognitive-motor control in monkeys. eNeuro 4:e0306.

Cappe C, Morel A, Barone P, Rouiller EM (2009) The thalamocortical projection systems in primate: an anatomical support for multisensory and sensorimotor interplay. Cereb Cortex 19:2025-2037.

Carmeli C, Lopez-Aguado L, Schmidt KE, De Feo O, Innocenti GM (2007) A novel interhemispheric interaction: modulation of neuronal cooperativity in the visual areas. PLoS One 2:e1287.

Carpenter AF, Baud-Bovy G, Georgopoulos AP, Pellizzer G (2018) Encod- 
ing of serial order in working memory: neuronal activity in motor, premotor, and prefrontal cortex during a memory scanning task. J Neurosci 38:4912-4933.

Carrera E, Tononi G (2014) Diaschisis: past, present, future. Brain 137: $2408-2422$.

Caspers S, Schleicher A, Bacha-Trams M, Palomero-Gallagher N, Amunts K, Zilles K (2013) Organization of the human inferior parietal lobule based on receptor architectonics. Cereb Cortex 23:615-628.

Catani M, Mesulam M (2008) What is a disconnection syndrome? Cortex 44:911-913.

Chafee MV, Goldman-Rakic PS (1998) Matching patterns of activity in primate prefrontal area $8 \mathrm{a}$ and parietal area 7ip neurons during a spatial working memory task. J Neurophysiol 79:2919-2940.

Chafee MV, Goldman-Rakic PS (2000) Inactivation of parietal and prefrontal cortex reveals interdependence of neural activity during memoryguided saccades. J Neurophysiol 83:1550-1566.

Chafee MV, Crowe DA, Averbeck BB, Georgopoulos AP (2005) Neural correlates of spatial judgement during object construction in parietal cortex. Cereb Cortex 15:1393-1413.

Chafee MV, Averbeck BB, Crowe DA (2007) Representing spatial relationships in posterior parietal cortex: single neurons code object-referenced position. Cereb Cortex 17:2914-2932.

Chen A, DeAngelis GC, Angelaki DE (2011) A comparison of vestibular spatiotemporal tuning in macaque parietoinsular vestibular cortex, ventral intraparietal area, and medial superior temporal area. J Neurosci 31:3082-3094.

Chen A, DeAngelis GC, Angelaki DE (2013) Functional specializations of the ventral intraparietal area for multisensory heading discrimination. J Neurosci 33:3567-3581.

Chen A, Gu Y, Liu S, DeAngelis GC, Angelaki DE (2016) Evidence for a causal contribution of macaque vestibular, but not intraparietal, cortex to heading perception. J Neurosci 36:3789-3798.

Chen LL, Wise SP (1996) Evolution of directional preferences in the supplementary eye field during acquisition of conditional oculomotor associations. J Neurosci 16:3067-3081.

Chen LL, Wise SP (1997) Conditional oculomotor learning: population vectors in the supplementary eye field. J Neurophysiol 78:1166-1169.

Chen SX, Kim AN, Peters AJ, Komiyama T (2015) Subtype-specific plasticity of inhibitory circuits in motor cortex during motor learning. Nat Neurosci 18:1109-1115.

Churchland MM, Yu BM, Ryu SI, Santhanam G, Shenoy KV (2006) Neural variability in premotor cortex provides a signature of motor preparation. J Neurosci 26:3697-3712.

Churchland MM, Cunningham JP, Kaufman MT, Ryu SI, Shenoy KV (2010) Cortical preparatory activity: representation of movement or first cog in a dynamical machine? Neuron 68:387-400.

Cisek P, Kalaska JF (2010) Neural mechanisms for interacting with a world full of action choices. Annu Rev Neurosci 33:269-298.

Colby CL, Duhamel JR, Goldberg ME (1993) Ventral intraparietal area of the macaque: anatomic location and visual response properties. J Neurophysiol 69:902-914.

Conti F, Rustioni A, Petrusz P, Towle AC (1987) Glutamate-positive neurons in the somatic sensory cortex of rats and monkeys. J Neurosci 7:1887-1901.

Conti F, Fabri M, Manzoni T (1988) Glutamate-positive corticocortical neurons in the somatic sensory areas I and II of cats. J Neurosci 8:29482960.

Coslett HB, Schwartz MF (2018) The parietal lobe and language. Handb Clin Neurol 151:365-375.

Crandall SR, Cruikshank SJ, Connors BW (2015) A corticothalamic switch: controlling the thalamus with dynamic synapses. Neuron 86:768-782.

Crowe DA, Chafee MV, Averbeck BB, Georgopoulos AP (2004a) Neural activity in primate parietal area 7a related to spatial analysis of visual mazes. Cereb Cortex 14:23-34.

Crowe DA, Chafee MV, Averbeck BB, Georgopoulos AP (2004b) Participation of primary motor cortical neurons in a distributed network during maze solution: representation of spatial parameters and time-course comparison with parietal area 7a. Exp Brain Res 158:28-34.

Crowe DA, Averbeck BB, Chafee MV, Georgopoulos AP (2005) Dynamics of parietal neural activity during spatial cognitive processing. Neuron 47:885-891.

Crowe DA, Averbeck BB, Chafee MV (2008) Neural ensemble decoding re- veals a correlate of viewer- to object-centered spatial transformation in monkey parietal cortex. J Neurosci 28:5218-5228.

Daitch AL, Parvizi J (2018) Spatial and temporal heterogeneity of neural responses in human posteromedial cortex. Proc Natl Acad Sci U S A 115:4785-4790.

Dann B, Michaels JA, Schaffelhofer S, Scherberger H (2016) Uniting functional network topology and oscillations in the fronto-parietal single unit network of behaving primates. eLife 5:e15719.

Darling WG, Pizzimenti MA, Morecraft RJ (2011) Functional recovery following motor cortex lesions in non-human primates: experimental implications for human stroke patients. J Integr Neurosci 10:353-384.

Dayan E, Cohen LG (2011) Neuroplasticity subserving motor skill learning. Neuron 72:443-454

DeFelipe J, Jones EG (1985) Vertical organization of $\gamma$-aminobutyric acidaccumulating intrinsic neuronal systems in monkey cerebral cortex. J Neurosci 5:3246-3260.

DeFelipe J, Conley M, Jones EG (1986) Long-range focal collateralization of axons arising from corticocortical cells in monkey sensory-motor cortex. J Neurosci 6:3749-3766

Duhamel JR, Colby CL, Goldberg ME (1998) Ventral intraparietal area of the macaque: congruent visual and somatic response properties. J Neurophysiol 79:126-136.

Dum RP, Strick PL (1991) The origin of corticospinal projections from the premotor areas in the frontal lobe. J Neurosci 11:667-689.

Ebbesen CL, Insanally MN, Kopec CD, Murakami M, Saiki A, Erlich JC (2018) More than just a "motor" recent surprises from the frontal cortex. J Neurosci 38:9402-9413.

Elsayed GF, Lara AH, Kaufman MT, Churchland MM, Cunningham JP (2016) Reorganization between preparatory and movement population responses in motor cortex. Nat Commun 7:13239.

Evarts EV (1981) Role of motor cortex in voluntary movements in primates. In: Handbook of physiology, the nervous system, motor control (Brooks VB, ed), pp 1083-1120. Bethesda, MD: American Physiological Society.

Fairén A, DeFelipe J, Regidor J (1984) Non-pyramidal neurons: general account. In: Cellular components of the cerebral cortex, Vol 1, Cereb cortex (Peters A, Jones EG, eds), pp 201-253. New York: Plenum.

Farkas T, Kis Z, Toldi J, Wolff JR (1999) Activation of the primary motor cortex by somatosensory stimulation in adult rats is mediated mainly by associational connections from the somatosensory cortex. Neuroscience 90:353-361

Ferezou I, Haiss F, Gentet LJ, Aronoff R, Weber B, Petersen CC (2007) Spatiotemporal dynamics of cortical sensorimotor integration in behaving mice. Neuron 56:907-923.

Fermin AS, Yoshida T, Yoshimoto J, Ito M, Tanaka SC, Doya K (2016) Model-based action planning involves cortico-cerebellar and basal ganglia networks. Sci Rep 6:31378.

Ferrari-Toniolo S, Visco-Comandini F, Papazachariadis O, Caminiti R, Battaglia-Mayer A (2015) Posterior parietal cortex encoding of dymanic hand force underlying hand-object interaction. J Neurosci 35:10899_ 10910.

Filippini M, Breveglieri R, Akhras MA, Bosco A, Chinellato E, Fattori P (2017) Decoding information for grasping from the macaque dorsomedial visual stream. J Neurosci 37:4311-4322.

Fitzpatrick D (1996) The functional organization of local circuits in visual cortex: insights from the study of tree shrew striate cortex. Cereb Cortex 6:329-341.

Fogassi L, Gallese V, Fadiga L, Luppino G, Matelli M, Rizzolatti G (1996) Coding of peripersonal space in inferior premotor cortex (area F4). J Neurophysiol 76:141-157.

Gaffan D, Harrison S (1988) Inferotemporal-frontal disconnection and fornix transection in visuomotor conditional learning by monkeys. Behav Brain Res 31:149-163.

Gaffan D, Harrison S (1989) A comparison of the effects of fornix transection and sulcus principalis ablation upon spatial learning by monkeys. Behav Brain Res 31:207-220.

Gail A, Klaes C, Westendorff S (2009) Implementation of spatial transformation rules for goal-directed reaching via gain modulation in monkey parietal and premotor cortex. J Neurosci 29:9490-9499.

Gainotti G, Trojano L (2017) Constructional apraxia. In: Handbook of clinical neurology, Vol 151 (Series 3): the parietal lobe (Vallar G, Coslet HB, eds), pp 331-348. Amsterdam: Elsevier.

Gazzaniga MS, Bogen JE, Sperry RW (1962) Some functional effects of sec- 
tioning the cerebral commissures in man. Proc Natl Acad Sci U S A 48:1765-1769.

Gentet LJ, Kremer Y, Taniguchi H, Huang ZJ, Staiger JF, Petersen CC (2012) Unique functional properties of somatostatin-expressing GABAergic neurons in mouse barrel cortex. Nat Neurosci 15:607-612.

Gentilucci M, Fogassi L, Luppino G, Matelli M, Camarda R, Rizzolatti G (1988) Functional organization of inferior area 6 in the macaque monkey: I. somatotopy and the control of proximal movements. Exp Brain Res 71:475-490.

Georgopoulos AP, Carpenter AF (2015) Coding of movements in the motor cortex. Curr Opin Neurobiol 33:34-39.

Georgopoulos AP, Stefanis CN (2007) Local shaping of function in the motor cortex: motor contrast, directional tuning. Brain Res Rev 55:383-389.

Georgopoulos AP, Lurito JT, Petrides M, Schwartz AB, Massey JT (1989) Mental rotation of the neuronal population vector. Science 243:234-236.

Georgopoulos AP, Taira M, Lukashin A (1993) Cognitive neurophysiology of the motor cortex. Science 260:47-52.

Geschwind N (1965) Disconnection syndromes in animals and man. Brain 88:237-294.

Ghosh S, Porter R (1988) Corticocortical synaptic influences on morphologically identified pyramidal neurones in the motor cortex of the monkey. J Physiol 400:617-629.

Gilman JP, Medalla M, Luebke JI (2017) Area-specific features of pyramidal neurons: a comparative study in mouse and rhesus monkey. Cereb Cortex 27:2078-2094.

Goulas A, Uylings HB, Stiers P (2012) Unravelling the intrinsic functional organization of the human lateral frontal cortex: a parcellation scheme based on resting state fMRI. J Neurosci 32:10238-10252.

Graziano MS (2016) Ethological action maps: a paradigm shift for the motor cortex. Trends Cogn Sci 20:121-132.

Graziano MS, Cooke DF (2006) Parieto-frontal interactions, personal space, and defensive behavior. Neuropsychologia 44:845-859.

Gréa H, Pisella L, Rossetti Y, Desmurget M, Tilikete C, Grafton S, Prablanc C, Vighetto A (2002) A lesion of the posterior parietal cortex disrupts online adjustments during aiming movements. Neuropsychologia 40:24712480.

Grewe BF, Gründemann J, Kitch LJ, Lecoq JA, Parker JG, Marshall JD, Larkin MC, Jercog PE, Grenier F, Li JZ, Lüthi A, Schnitzer MJ (2017) Neural ensemble dynamics underlying a long-term associative memory. Nature 543:670-675.

Grillner S, Wallén P (2004) Innate versus learned movements: a false dichotomy? Prog Brain Res 143:3-12.

Guillery RW (1995) Anatomical evidence concerning the role of the thalamus in corticocortical communication: a brief review. J Anat 187:583592.

Guillery RW, Sherman SM (2002) Thalamic relay functions and their role in corticocortical communication: generalizations from the visual system. Neuron 33:163-175.

Hannah R, Cavanagh SE, Tremblay S, Simeoni S, Rothwell JC (2018) Selective suppression of local interneuron circuits in human motor cortex contributes to movement preparation. J Neurosci 38:1264-1276.

Hasegawa M, Majima K, Itokazu T, Maki T, Albrecht UR, Castner N, Izumo M, Sohya K, Sato TK, Kamitani Y, Sato TR (2017) Selective suppression of local circuits during movement preparation in the mouse motor cortex. Cell Rep 18:2676-2686.

Hécaen H, De Ajuriaguerra J (1954) Bálint's syndrome (psychic paralysis of visual fixation) and its minor forms. Brain 77:373-400.

Heilman KM, Valenstein E, Watson RT (2000) Neglect and related disorders. Semin Neurol 20:463-470.

Hihara S, Notoya T, Tanaka M, Ichinose S, Ojima H, Obayashi S, Fujii N, Iriki A (2006) Extension of corticocortical afferents into the anterior bank of the intraparietal sulcus by tool-use training in adult monkeys. Neuropsychologia 44:2636-2646.

Hoshi E, Tremblay L, Féger J, Carras PL, Strick PL (2005) The cerebellum communicates with the basal ganglia. Nat Neurosci 8:1491-1493.

Hosp JA, Pekanovic A, Rioult-Pedotti MS, Luft AR (2011) Dopaminergic projections from midbrain to primary motor cortex mediate motor skill learning. J Neurosci 31:2481-2487.

Huber D, Gutnisky DA, Peron S, O’Connor DH, Wiegert JS, Tian L, Oertner TG, Looger LL, Svoboda K (2012) Multiple dynamic representations in the motor cortex during sensorimotor learning. Nature 484:473-478.
Hultborn H, Lindström S, Wigström H (1979) On the function of recurrent inhibition in the spinal cord. Exp Brain Res 37:399-403.

Huntley GW, Jones EG (1991) Relationship of intrinsic connections to forelimb movement representations in monkey motor cortex: a correlative anatomic and physiological study. J Neurophysiol 66:390-413.

Innocenti GM, Vercelli A, Caminiti R (2014) The diameter of cortical axons depends both on the area of origin and target. Cereb Cortex 24:21782188 .

Innocenti GM, Carlén M, Dyrby TB (2016) The diameters of cortical axons and their relevance to neural computing. In: Axons and brain architeture (Rockland, KS, ed), pp 317-335. Amsterdam: Elsevier.

Innocenti GM, Caminiti R, Rouiller EM, Knott G, Dyrby TB, Descoteaux M, Thiran JP (2019) Diversity of cortico-descending projections: histological and diffusion MRI characterization in the monkey. Cereb Cortex 29:788-801.

Iriki A, Pavlides C, Keller A, Asanuma H (1989) Long-term potentiation in the motor cortex. Science 245:385-390.

Iriki A, Tanaka M, Iwamura Y (1996) Coding of modified body schema during tool use by macaque postcentral neurones. Neuroreport 7:23252330 .

Jiang X, Shen S, Cadwell CR, Berens P, Sinz F, Ecker AS, Patel S, Tolias AS (2015) Principles of connectivity among morphologically defined cell types in adult neocortex. Science 350:aac9462.

Johnson PB, Angelucci A, Ziparo RM, Minciacchi D, Bentivoglio M, Caminiti R (1989) Segregation and overlap of callosal and association neurons in frontal and parietal cortices of primates: a spectral and coherency analysis. J Neurosci 9:2313-2326.

Johnson PB, Ferraina S, Bianchi L, Caminiti R (1996) Cortical networks for visual reaching: physiological and anatomical organization of frontal and parietal lobe arm regions. Cereb Cortex 6:102-119.

Jones EG (1975) Variety and distribution of non-pyramidal cells in the somatic-sensory cortex of squirrel monkey. J Comp Neurol 160:205-267.

Jones EG, Coulter JD, Hendry SH (1978) Intracortical connectivity of architectonic fields in the somatic sensory, motor and parietal cortex of monkeys. J Comp Neurol 181:291-347.

Kaas JH, Qi HX, Stepniewska I (2018) The evolution of parietal cortex in primates. Handb Clin Neurol 151:31-52.

Kalaska JF, Caminiti R, Georgopoulos AP (1983) Cortical mechanisms related to direction of two-dimensional arm movements: relations in parietal area 5 and comparison with motor cortex. Exp Brain Res 51:247-260.

Kaufman MT, Churchland MM, Ryu SI, Shenoy KV (2014) Cortical activity in the null space: permitting preparation without movement. Nat Neurosci 17:440-448.

Kawai R, Markman T, Poddar R, Ko R, Fantana AL, Dhawale AK, Kampff AR, Olveczky BP (2015) Motor cortex is required for learning but not for executing a motor skill. Neuron 86:800-812.

Keck T, Keller GB, Jacobsen RI, Eysel UT, Bonhoeffer T, Hübener M (2013) Synaptic scaling and homeostatic plasticity in the mouse visual cortex in vivo. Neuron 80:327-334.

Keller A (1993) Intrinsic synaptic organization of the motor cortex. Cereb Cortex 3:430-441.

Keller A, Asanuma H (1993) Synaptic relationships involving local axon collaterals of pyramidal neurons in the cat motor cortex. J Comp Neurol 336:229-242.

Keller A, Miyashita E, Asanuma H (1991) Minimal stimulus parameters and the effects of hyperpolarization on the induction of long-term potentiation in the cat motor cortex. Exp Brain Res 87:295-302.

Kiani R, Shadlen MN (2009) Representation of confidence associated with a decision by neurons in the parietal cortex. Science 324:759-764.

Kisvárday ZF, Eysel UT (1992) Cellular organization of reciprocal patchy network in layer III of cat visual cortex (area 17). Neuroscience 46:275286.

Kleinfeld D, Sachdev RN, Merchant LM, Jarvis MR, Ebner FF (2002) Adaptive filtering of vibrissa input in motor cortex of rat. Neuron 34:10211034.

Kleist K (1934) Konstruktive (optische) Apraxie. Leipzig, Germany: Barth.

Komiyama T, Sato TR, O'Connor DH, Zhang YX, Huber D, Hooks BM, Gabitto M, Svoboda K (2010) Learning-related fine-scale specificity imaged in motor cortex circuits of behaving mice. Nature 464:1182-1186.

Komura Y, Nikkuni A, Hirashima N, Uetake T, Miyamoto A (2013) Responses of pulvinar neurons reflect a subject's confidence in visual categorization. Nat Neurosci 16:749-755. 
Kravitz DJ, Saleem KS, Baker CI, Mishkin M (2011) A new neural framework for visuospatial processing. Nat Rev Neurosci 12:217-230.

Krubitzer L, Campi KL, Cooke DF (2011) All rodents are not the same: a modern synthesis of cortical organization. Brain Behav Evol 78:51-93.

Kwan HC, MacKay WA, Murphy JT, Wong YC (1978a) An intracortical microstimulation study of output organization in precentral cortex of awake primates. J Physiol (Paris) 74:231-233.

Kwan HC, MacKay WA, Murphy JT, Wong YC (1978b) Spatial organization of precentral cortex in awake primates: II. Motor outputs. J Neurophysiol 41:1120-1131.

Lacquaniti F, Guigon E, Bianchi L, Ferraina S, Caminiti R (1995) Representing spatial information for limb movement: the role of area 5 in the monkey. Cereb Cortex 5:391-409.

Lanzilotto M, Livi A, Maranesi M, Gerbella M, Barz F, Ruther P, Fogassi L, Rizzolatti G, Bonini L (2016) Extending the cortical grasping network: pre-supplementary motor neuron activity during vision and grasping of objects. Cereb Cortex 26:4435-4449.

Lee D, Seo H, Jung MW (2012) Neural basis of reinforcement learning and decision making. Annu Rev Neurosci 35:287-308.

Leichnetz GR (2001) Connections of the medial posterior parietal cortex (area $7 \mathrm{~m}$ ) in the monkey. Anat Rec 263: 215-236.

Li CS, Padoa-Schioppa C, Bizzi E (2001) Neuronal correlates of motor performance and motor learning in the primary motor cortex of monkeys adapting to an external force field. Neuron 30:593-607.

Lichtheim L (1885) On aphasia. Brain 7:433-484.

Luebke JI (2017) Pyramidal neurons are not generalizable building blocks of cortical networks. Front Neuroanat 11:11.

Lund JS, Yoshioka T, Levitt JB (1993) Comparison of intrinsic connectivity in different areas of macaque monkey cerebral cortex. Cereb Cortex 3:148-162.

Mahan MY, Georgopoulos AP (2013) Motor directional tuning across brain areas: directional resonance and the role of inhibition for directional accuracy. Front Neural Circuits 7:92.

Makino H, Hwang EJ, Hedrick NG, Komiyama T (2016) Circuit mechanisms of sensorimotor learning. Neuron 92:705-721.

Mao T, Kusefoglu D, Hooks BM, Huber D, Petreanu L, Svoboda K (2011) Long-range neuronal circuits underlying the interaction between sensory and motor cortex. Neuron 72:111-123.

Marder E, Goaillard JM (2006) Variability, compensation and homeostasis in neuron and network function. Nat Rev Neurosci 7:563-574.

Markov NT, Ercsey-Ravasz M, Van Essen DC, Knoblauch K, Toroczkai Z, Kennedy H (2013) Cortical high-density counterstream architectures. Science 342:1238406.

Mars RB, Jbabdi S, Sallet J, O'Reilly JX, Croxson PL, Olivier E, Noonan MP, Bergmann C, Mitchell AS, Baxter MG, Behrens TE, Johansen-Berg H, Tomassini V, Miller KL, Rushworth MF (2011) Diffusion-weighted imaging tractography-based parcellation of the human parietal cortex and comparison with human and macaque resting-state functional connectivity. J Neurosci 31:4087-4100.

Mars RB, Passingham RE, Jbabdi S (2018) Connectivity fingerprints: from areal descriptions to abstract spaces. Trends Cogn Sci 22:1026-1037.

Martínez-Vázquez P, Gail A (2018) Directed interaction between monkey premotor and posterior parietal cortex during motor-goal retrieval from working memory. Cereb Cortex 28:1866-1881.

Masamizu Y, Tanaka YR, Tanaka YH, Hira R, Ohkubo F, Kitamura K, Isomura Y, Okada T, Matsuzaki M (2014) Two distinct layer-specific dynamics of cortical ensembles during learning of a motor task. Nat Neurosci 17:987-994.

Mascaro M, Battaglia-Mayer A, Nasi L, Amit DJ, Caminiti R (2003) The eye and the hand: neural mechanisms and network models for oculomanual coordination. Cereb Cortex 13:1276-1286.

Matelli M, Govoni P, Galletti C, Kutz DF, Luppino G (1998) Superior area 6 afferents from the superior parietal lobule in the macaque monkey. J Comp Neurol 402:327-352.

Mattia M, Pani P, Mirabella G, Costa S, Del Giudice P, Ferraina S (2013) Heterogeneous attractor cell assemblies for motor planning in premotor cortex. J Neurosci 33:11155-11168.

Mattingley JB, Bradshaw JL, Phillips JG (1992) Impairments of movement initiation and execution in unilateral neglect: directional hypokinesia and bradykinesia. Brain 115:1849-1874.

McGuire LM, Sabes PN (2009) Sensory transformations and the use of multiple reference frames for reach planning. Nat Neurosci 12:1056-1061.
Merchant H, Battaglia-Mayer A, Georgopoulos AP (2003) Functional organization of parietal neuronal responses to optic-flow stimuli. J Neurophysiol 90:675-682.

Michaels JA, Dann B, Intveld RW, Scherberger H (2015) Predicting reaction time from the neural state space of the premotor and parietal grasping network. J Neurosci 35:11415-11432.

Mione V, Canterini S, Brunamonti E, Pani P, Donno F, Fiorenza MT, Ferraina S (2015) Both the COMT Val158Met single-nucleotide polymorphism and sex-dependent differences influence response inhibition. Front Behav Neurosci 9:127.

Mirabella G, Pani P, Ferraina S (2011) Neural correlates of cognitive control of reaching movements in the dorsal premotor cortex of rhesus monkeys. J Neurophysiol 106:1454-1466.

Mitz AR, Godschalk M, Wise SP (1991) Learning-dependent neuronal activity in the premotor cortex of rhesus monkeys. J Neurosci 11:18551872.

Moll L, Kuypers HG (1977) Premotor cortical ablations in monkeys: contralateral changes in visually guided reaching behavior. Science 198: 317-319.

Mountcastle VB (1978) An organizing principle for cerebral function: the unit model and the distributed system. In: The mindful brain (Mountcastle VB, Edelmann G, eds). Cambridge, MA: Massachusetts Institute of Technology.

Mountcastle VB (2005) The sensory hand. In: Neural mechanisms of somatic sensation. Cambridge MA: Harvard UP.

Mundinano IC, Fox DM, Kwan WC, Vidaurre D, Teo L, Homman-Ludiye J, Goodale MA, Leopold DA, Bourne JA (2018) Transient visual pathway critical for normal development of primate grasping behavior. Proc Natl Acad Sci U S A 115:1364-1369.

Nelissen K, Fiave PA, Vanduffel W (2018) Decoding grasping movements from the parieto-frontal reaching circuit in the nonhuman primate. Cereb Cortex 28:1245-1259.

Neubert FX, Mars RB, Thomas AG, Sallet J, Rushworth MF (2014) Comparison of human ventral frontal cortex areas for cognitive control and language with areas in monkey frontal cortex. Neuron: 81:700-713.

Newsome WT, Paré EB (1988) A selective impairment of motion perception following lesions of the middle temporal visual area (MT). J Neurosci 8:2201-2211.

Nieder A (2016) The neuronal code for number. Nat Rev Neurosci 17:366382.

Nieder A, Dehaene S (2009) Representation of number in the brain. Annu Rev Neurosci 32:185-208.

Ninomiya T, Dougherty K, Godlove DC, Schall JD, Maier, A (2015) Microcircuitry of agranular frontal cortex: contrasting laminar connectivity between occipital and frontal areas. J Neurophysiol 113:3242-3255.

Obayashi S, Tanaka M, Iriki A (2000) Subjective image of invisible hand coded by monkey intraparietal neurons. Neuroreport 11:3499-3505.

Olcese U, Iurilli G, Medini P (2013) Cellular and synaptic architecture of multisensory integration in the mouse neocortex. Neuron 79:579-593.

Orban GA, Claeys K, Nelissen K, Smans R, Sunaert S, Todd JT, Wardak C, Durand JB, Vanduffel W (2006) Mapping the parietal cortex of humans and non-human primates. Neuropsychologia 44:2647-2667.

O'Shea DJ, Shenoy KV (2016) The importance of planning in motor learning Neuron 92:669-671.

Otchy TM, Wolff SB, Rhee JY, Pehlevan C, Kawai R, Kempf A, Gobes SM, Ölveczky BP (2015) Acute off-target effects of neural circuit manipulations. Nature 528:358-363.

Packer AM, Yuste R (2011) Dense, unspecific connectivity of neocortical parvalbumin-positive interneurons: a canonical microcircuit for inhibition? J Neurosci 31:13260-13271.

Padberg J, Franca JG, Cooke DF, Soares JG, Rosa MG, Fiorani M Jr, Gattass R, Krubitzer L (2007) Parallel evolution of cortical areas involved in skilled hand use. J Neurosci 27:10106-10115.

Padberg J, Recanzone G, Engle J, Cooke D, Goldring A, Krubitzer L (2010) Lesions in posterior parietal area 5 in monkeys result in rapid behavioral and cortical plasticity. J Neurosci 30:12918-12935.

Padoa-Schioppa C, Li CS, Bizzi E (2004) Neuronal activity in the supplementary motor area of monkeys adapting to a new dynamic environment. J Neurophysiol 91:449-473.

Passingham RE, Stephan KE, Kötter R (2002) The anatomical basis of functional localization in the cortex. Nat Rev Neurosci 3:606-616. 
Pasupathy A, Miller EK (2005) Different time courses of learning-related activity in the prefrontal cortex and striatum. Nature 433:873-876.

Peeters R, Simone L, Nelissen K, Fabbri-Destro M, Vanduffel W, Rizzolatti G, Orban GA (2009) The representation of tool use in humans and monkeys: common and uniquely human features. J Neurosci 29:11523-11539.

Pellizzer G, Sargent P, Georgopoulos AP (1995) Motor cortical activity in a context-recall task. Science 269:702-705.

Pesaran B, Nelson MJ, Andersen RA (2006) Dorsal premotor neurons encode the relative position of the hand, eye, and goal during reach planning. Neuron 51:125-134.

Pesaran B, Nelson MJ, Andersen RA (2008) Free choice activates a decision circuit between frontal and parietal cortex. Nature 453:406-409.

Peters AJ, Chen SX, Komiyama T (2014) Emergence of reproducible spatiotemporal activity during motor learning. Nature 510:263-267.

Petreanu L, Gutnisky DA, Huber D, Xu NL, O'Connor DH, Tian L, Looger L, Svoboda K (2012) Activity in motor-sensory projections reveals distributed coding in somatosensation. Nature 489:299-303.

Petrides M (1982) Motor conditional associative-learning after selective prefrontal lesions in the monkey. Behav Brain Res 5:407-413.

Petrides M (1985) Deficits on conditional associative-learning tasks after frontal-and temporal-lobe lesions in man. Neuropsychologia 23:601614.

Picard N, Strick PL (1996) Motor areas of the medial wall: a review of their location and functional activation. Cereb Cortex 6:342-353.

Pisella L, Gréa H, Tilikete C, Vighetto A, Desmurget M, Rode G, Boisson D, Rossetti Y (2000) An 'automatic pilot' for the hand in human posterior parietal cortex: toward reinterpreting optic ataxia. Nat Neurosci 3:729736.

Piserchia V, Breveglieri R, Hadjidimitrakis K, Bertozzi F, Galletti C, Fattori P (2017) Mixed body/hand reference frame for reaching in 3D space in macaque parietal area PEc. Cereb Cortex 27:1976-1990.

Poliakov AV, Schieber MH (1999) Limited functional grouping of neurons in the motor cortex hand area during individuated finger movements: a cluster analysis. J Neurophysiol 82:3488-3505.

Pratt KG, Prather JF (2016) Systems neuroscience: how the cortex contributes to skilled movements. Curr Biol 26:R64-R66.

Pritz MB (1995) The thalamus of reptiles and mammals: similarities and differences. Brain Behav Evol 46:197-208.

Prut Y, Fetz EE (1999) Primate spinal interneurons show pre-movement instructed delay activity. Nature 401:590-594.

Ramamurthy DL, Krubitzer LA (2018) Neural coding of whisker-mediated touch in primary somatosensory cortex is altered following early blindness. J Neurosci 38:6172-6189.

Rathelot JA, Strick PL (2009) Subdivisions of primary motor cortex based on cortico-motoneuronal cells. Proc Natl Acad Sci U S A 106:918-923.

Rathelot JA, Dum RP, Strick PL (2017) Posterior parietal cortex contains a command apparatus for hand movements. Proc Natl Acad Sci U S A 114:4255-4260.

Renshaw B (1941) Influence of discharge of motoneurons upon excitation of neighboring motoneurons. J Neurophysiol 4:167-183.

Reynolds C, Ashby P (1999) Inhibition in the human motor cortex is reduced just before a voluntary contraction. Neurology 53:730-735.

Richter M, Amunts K, Mohlberg H, Bludau S, Eickhoff SB, Zilles K, Caspers S (2019) Cytoarchitectonic segregation of human posterior intraparietal and adjacent parieto-occipital sulcus and its relation to visuomotor and cognitive functions. Cereb Cortex 29:1305-1327.

Rikhye RV, Gilra A, Halassa MM (2018a) Thalamic regulation of switching between cortical representations enables cognitive flexibility. Nat Neurosci 21:1753-1763.

Rikhye RV, Wimmer RD, Halassa MM (2018b) Toward an integrative theory of thalamic function. Annu Rev Neurosci 41:163-183.

Rioult-Pedotti MS, Friedman D, Hess G, Donoghue JP (1998) Strengthening of horizontal cortical connections following skill learning. Nat Neurosci 1:230-234.

Rioult-Pedotti MS, Friedman D, Donoghue JP (2000) Learning-induced LTP in neocortex. Science 290:533-536.

Rizzolatti G, Matelli M, Pavesi G (1983) Deficits in attention and movement following the removal of postarcuate (area 6) and prearcuate (area 8) cortex in macaque monkeys. Brain 106:655-673.

Rizzolatti G, Cattaneo L, Fabbri-Destro M, Rozzi S (2014) Cortical mechanisms underlying the organization of goal-directed actions and mirror neuron-based action understanding. Physiol Rev 94:655-706.
Rockland KS (2015) About connections. Front Neuroanat 9:61.

Rockland KS (2018) Axon collaterals and brain states. Front Syst Neurosci 12:32.

Rockland KS (2019) Corticothalamic axon morphologies and network architecture. Eur J Neurosci 49:969-977.

Rokni U, Richardson AG, Bizzi E, Seung HS (2007) Motor learning with unstable neural representations. Neuron 54:653-666.

Rossetti Y, Pisella L (2018) Optic ataxia: beyond the dorsal stream cliché. Handb Clin Neurol 151:225-247.

Ruschel M, Knösche TR, Friederici AD, Turner R, Geyer S, Anwander A (2014) Connectivity architecture and subdivision of the human inferior parietal cortex revealed by diffusion MRI. Cereb Cortex 24:2436-2448.

Rushworth MF, Behrens TE, Johansen-Berg H (2006) Connection patterns distinguish 3 regions of human parietal cortex. Cereb Cortex 16:14181430.

Russo AA, Bittner SR, Perkins SM, Seely JS, London BM, Lara AH, Miri A, Marshall NJ, Kohn A, Jessell TM, Abbott LF, Cunningham JP, Churchland MM (2018) Motor cortex embeds muscle-like commands in an untangled population response. Neuron 97:953-966.e8.

Sabes PN (2000) The planning and control of reaching movements. Curr Opin Neurobiol 10:740-746.

Sabes PN (2011) Sensory integration for reaching: models of optimality in the context of behavior and the underlying neural circuits. Prog Brain Res 191:195-209.

Safavi S, Dwarakanath A, Kapoor V, Werner J, Hatsopoulos NG, Logothetis NK, Panagiotaropoulos TI (2018) Nonmonotonic spatial structure of interneuronal correlations in prefrontal microcircuits. Proc Natl Acad Sci U S A 115:E3539-E3548.

Sajad A, Godlove DC, Schall JD (2019) Cortical microcircuitry of performance monitoring. Nat Neurosci 22:265-274.

Sallet J, Mars RB, Noonan MP, Neubert FX, Jbabdi S, O’Reilly JX, Filippini N, Thomas AG, Rushworth MF (2013) The organization of dorsal frontal cortex in humans and macaques. J Neurosci 33:12255-12274.

Sanes JN, Donoghue JP (2000) Plasticity and primary motor cortex. Annu Rev Neurosci 23:393-415.

Sawaguchi T, Yamane I, Kubota K (1996) Application of the GABA antagonist bicuculline to the premotor cortex reduces the ability to withhold reaching movements by well-trained monkeys in visually guided reaching task. J Neurophysiol 75:2150-2156.

Schaffelhofer S, Scherberger H (2016) Object vision to hand action in macaque parietal, premotor, and motor cortices. eLife 5:e15278.

Schieber MH (2000) Inactivation of the ventral premotor cortex biases the laterality of motoric choices. Exp Brain Res 130:497-507.

Schlack A, Hoffmann KP, Bremmer F (2002) Interaction of linear vestibular and visual stimulation in the macaque ventral intraparietal area (VIP). Eur J Neurosci 16:1877-1886.

Schlack A, Sterbing-D’Angelo SJ, Hartung K, Hoffmann KP, Bremmer F (2005) Multisensory space representations in the macaque ventral intraparietal area. J Neurosci 25:4616-4625.

Schmitt LI, Wimmer RD, Nakajima M, Happ M, Mofakham S, Halassa MM (2017) Thalamic amplification of cortical connectivity sustains attentional control. Nature 545:219-223.

Schultz W (2015) Neuronal reward and decision signals: from theories to data. Physiol Rev 95:853-951.

Schultz W (2016) Dopamine reward prediction-error signaling: a twocomponent response. Nat Rev Neurosci 17:183-195.

Sheahan HR, Franklin DW, Wolpert DM (2016) Motor planning, not execution, separates motor memories. Neuron 92:773-779.

Sherman SM (2016) Thalamus plays a central role in ongoing cortical functioning. Nat Neurosci 119:533-541.

Sherman SM (2017) Functioning of circuits connecting thalamus and cortex. Compr Physiol 7:713-739.

Shinoda Y, Yokota J, Futami T (1981) Divergent projection of individual corticospinal axons to motoneurons of multiple muscles in the monkey. Neurosci Lett 23:7-12.

Shmuelof L, Krakauer JW (2011) Are we ready for a natural history of motor learning? Neuron 72:469-476.

Silasi G, Murphy TH (2014) Stroke and the connectome: how connectivity guides therapeutic intervention. Neuron 83:1354-1368.

Simone L, Rozzi S, Bimbi M, Fogassi L (2015) Movement-related activity during goal-directed hand actions in the monkey ventrolateral prefrontal cortex. Eur J Neurosci 42:2882-2894. 
Smith MA, Kohn A (2008) Spatial and temporal scales of neuronal correlation in primary visual cortex. J Neurosci 28:12591-12603.

Smith MA, Sommer MA (2013) Spatial and temporal scales of neuronal correlation in visual area V4. J Neurosci 33:5422-5432.

Snyder LH, Batista AP, Andersen RA (1997) Coding of intention in the posterior parietal cortex. Nature 386:167-170.

Soteropoulos DS (2018) Corticospinal gating during action preparation and movement in the primate motor cortex. J Neurophysiol 119:15381555.

Sperry RW (1968) Hemisphere deconnection and unity in consciousness. Am Psychol 23:723-733.

Sporns O (2012) Networks of the brain. Cambridge MA: Massachusetts Institute of Technology.

Stefanis C, Jasper H (1964) Recurrent collateral inhibition in pyramidal tract neurons. J Neurophysiol 27:855-877.

Stoelzel CR, Bereshpolova Y, Alonso JM, Swadlow HA (2017) Axonal conduction delays, brain state, and corticogeniculate communication. J Neurosci 37:6342-6358.

Swadlow HA, Rosene DL, Waxman SG (1978) Characteristics of interhemispheric impulse conduction between prelunate gyri of the rhesus monkey. Exp Brain Res 33:455-467.

Talwar SK, Musial PG, Gerstein GL (2001) Role of mammalian auditory cortex in the perception of elementary sound properties. J Neurophysiol $85: 2350-2358$.

Tokuno H, Nambu A (2000) Organization of nonprimary motor cortical inputs on pyramidal and nonpyramidal tract neurons of primary motor cortex: an electrophysiological study in the macaque monkey. Cereb Cortex 10:58-68.

Tomasi S, Caminiti R, Innocenti GM (2012) Areal differences in diameter and length of corticofugal projections. Cereb Cortex 22:1463-1472.

Toni I, Passingham RE (1999) Prefrontal-basal ganglia pathways are involved in the learning of arbitrary visuomotor associations: a PET study. Exp Brain Res 127:19-32.

Tremblay L, Hollerman JR, Schultz W (1998) Modifications of reward expectation-related neuronal activity during learning in primate striatum. J Neurophysiol 80:964-977.

Turrigiano GG (1999) Homeostatic plasticity in neuronal networks: the more things change, the more they stay the same. Trends Neurosci 22:221-227.

Ungerleider LG, Doyon J, Karni A (2002) Imaging brain plasticity during motor skill learning. Neurobiol Learn Mem 78:553-564.

Vallar G, Bolognini N (2014) Unilateral spatial neglect. In: Oxford handbook of attention (Nobre AC, Kastner S, eds), pp 972-1024. Oxford: Oxford UP.

van Aerde KI, Feldmeyer D (2015) Morphological and physiological characterization of pyramidal neuron subtypes in rat medial prefrontal cortex. Cereb Cortex 25:788-805.

van den Heuvel MP, Sporns O, Collin G, Scheewe T, Mandl RC, Cahn W, Goñi J, Hulshoff Pol HE, Kahn RS (2013) Abnormal rich club organization and functional brain dynamics in schizophrenia. JAMA Psychiatry 70:783-792.

Van Essen DC (2002) Windows on the brain. the emerging role of atlases and databases in neuroscience. Curr Opin Neurobiol 12:574-579.

Van Essen DC, Smith SM, Barch DM, Behrens TE, Yacoub E, Ugurbil K (2013) The WU-minn human connectome project: an overview. Neuroimage 80:62-79.

Vijayakumar S, Sallet J, Verhagen L, Folloni D, Medendorp WP, Mars RB (2019) Mapping multiple principles of parietal-frontal cortical organization using functional connectivity. Brain Struct Funct 224:681-697.

Wang Q, Burkhalter A (2007) Area map of mouse visual cortex. J Comp Neurol 502:339-357.

Wang Q, Sporns O, Burkhalter A (2012) Network analysis of corticocortical connections reveals ventral and dorsal processing streams in mouse visual cortex. J Neurosci 32:4386-4399.
Watts DJ, Strogatz SH (1998) Collective dynamics of 'small world' networks. Nature 393:440-442.

Weiler N, Wood L, Yu J, Solla SA, Shepherd GM (2008) Top-down laminar organization of the excitatory network in motor cortex. Nat Neurosci 11:360-366.

Wernicke C (1874) Der Aphasische Symptomenkomplex. Breslau, Poland: Cohn Weigart.

Westendorff S, Klaes C, Gail A (2010) The cortical timeline for deciding on reach motor goals. J Neurosci 30:5426-5436.

Whitlock JR, Sutherland RJ, Witter MP, Moser MB, Moser EI (2008) Navigating from hippocampus to parietal cortex. Proc Natl Acad Sci U S A 105:14755-14762.

Wilke M, Turchi J, Smith K, Mishkin M, Leopold DA (2010) Pulvinar inactivation disrupts selection of movement plans. J Neurosci 30:8650-8659.

Wilson FA, Scalaidhe SP, Goldman-Rakic PS (1993) Dissociation of object and spatial processing domains in primate prefrontal cortex. Science 260:1955-1958.

Wise SP, Murray EA (1999) Role of the hippocampal system in conditional motor learning: mapping antecedents to action. Hippocampus 9:101117.

Wise SP, Murray EA (2000) Arbitrary associations between antecedents and actions. Trends Neurosci 23:271-276.

Wise SP, Boussaoud D, Johnson PB, Caminiti R (1997) Premotor and parietal cortex: cortico-cortical connectivity and combinatorial computations. Annu Rev Neurosci 20:25-42.

Wise SP, Moody SL, Blomstrom KJ, Mitz AR (1998) Changes in motor cortical activity during visuomotor adaptation. Exp Brain Res 121:285-299.

Witham CL, Fisher KM, Edgley SA, Baker SN (2016) Corticospinal inputs to primate motoneurons innervating the forelimb from two divisions of primary motor cortex and area 3a. J Neurosci 36:2605-2616.

Wolff M, Vann SD (2019) The cognitive thalamus as a gateway to mental representations. J Neurosci 39:3-14.

Wolpert DM, Miall RC (1996) Forward models for physiological motor control. Neural Netw 9:1265-1279.

Wolpert DM, Diedrichsen J, Flanagan JR (2011) Principles of sensorimotor learning. Nat Rev Neurosci 12:739-751.

Xiang JZ, Brown MW (1999) Differential neuronal responsiveness in primate perirhinal cortex and hippocampal formation during performance of a conditional visual discrimination task. Eur J Neurosci 11:3715-3724.

Xu C, Krabbe S, Gründemann J, Botta P, Fadok JP, Osakada F, Saur D, Grewe BF, Schnitzer MJ, Callaway EM, Lüthi A (2016) Distinct hippocampal pathways mediate dissociable roles of context in memory retrieval. Cell 167:961-972.e16.

Xu NL, Harnett MT, Williams SR, Huber D, O'Connor DH, Svoboda K, Magee JC (2012) Nonlinear dendritic integration of sensory and motor input during an active sensing task. Nature 492:247-251.

Xu T, Yu X, Perlik AJ, Tobin WF, Zweig JA, Tennant K, Jones T, Zuo Y (2009) Rapid formation and selective stabilization of synapses for enduring motor memories. Nature 462:915-919.

Yamashita T, Vavladeli A, Pala A, Galan K, Crochet S, Petersen SS, Petersen CC (2018) Diverse long-range axonal projections of excitatory layer $2 / 3$ neurons in mouse barrel cortex. Front Neuroanat 12:33.

Yang G, Pan F, Gan WB (2009) Stably maintained dendritic spines are associated with lifelong memories. Nature 462:920-924.

Yang M, Logothetis NK, Eschenko O (2019) Occurrence of hippocampal ripples is associated with activity suppression in the mediodorsal thalamic nucleus. J Neurosci 39:434-444.

Zaaimi B, Edgley SA, Soteropoulos DS, Baker SN (2012) Changes in descending motor pathway connectivity after corticospinal tract lesion in macaque monkey. Brain 135:2277-2289.

Zach N, Inbar D, Grinvald Y, Bergman H, Vaadia E (2008) Emergence of novel representations in primary motor cortex and premotor neurons during associative learning. J Neurosci 28:9545-9556. 